\title{
Temporal and Qualitative Dynamics of Conditioned Taste Aversion Processing: Combined Generalization Testing and Licking Microstructure Analysis
}

\author{
John-Paul Baird \\ Amherst College
}

\author{
Steven James St. John \\ Reed College
}

\author{
Eric Anh-Nhat Nguyen \\ Amherst College
}

\begin{abstract}
The pattern of licking microstructure during various phases of a conditioned taste aversion (CTA) was evaluated. In Experiment 1, rats ingested lithium chloride ( $\mathrm{LiCl}$ ) for 3 trials and were then offered sodium chloride $(\mathrm{NaCl})$ or sucrose on 3 trials. A CTA to $\mathrm{LiCl}$ developed and generalized to $\mathrm{NaCl}$ but not to sucrose. CTA intake suppression was characterized by reductions in burst size, average ingestion rate, and intraburst lick rate, and increases in brief pauses and burst counts. Compared with previous studies, $\mathrm{LiCl}$ licking shifted from a pattern initially matching that for normally accepted $\mathrm{NaCl}$ to one matching licking for normally avoided quinine hydrochloride by the end of the 1st acquisition trial. In Experiment 2 , a novel paradigm was developed to show that rats expressed CTA generalization within 9 min of their first $\mathrm{LiCl}$ access. These results suggest that licking microstructure analysis can be used to assay changes in hedonic evaluation caused by treatments that produce aversive states.
\end{abstract}

Keywords: taste, licking, microstructure, aversion, learning
When intake of a novel tastant is followed by the injection of a toxin — for example, lithium chloride ( $\mathrm{LiCl}$ ) — animals form a conditioned taste aversion (CTA) and subsequently avoid that tastant (e.g., Garcia, Kimeldorf, \& Koelling, 1955; see also Riley \& Freeman, 2003). This model has been widely used to investigate behavioral and neural mechanisms of taste-visceral integration, learning, and memory and to identify therapeutic targets for clinical conditions such as cancer anorexia (Bernstein, 1985, 1999; Jacobsen et al., 1993; Rodriguez, Lopez, Symonds, \& Hall, 2000; Welzl, D'Adamo, \& Lipp, 2001).

The traditional measure of CTA is intake of the novel tastant before and after toxin exposure, relative either to control animals that do not receive toxin and/or to water intake in two-bottle preference tests. Although they are widely accepted, intake measurements per se cannot indicate how CTA-related neural or drug treatments affect

John-Paul Baird and Eric Anh-Nhat Nguyen, Department of Psychology, Amherst College; Steven James St. John, Department of Psychology, Reed College.

Portions of these data were collected for academic credit for Eric Anh-Nhat Nguyen and presented at the April 2004 and April 2005 meetings of the Association for Chemoreception, Sarasota, Florida. This research was supported by Amherst College, a Mellon- 8 grant from the Andrew Mellon Foundation to John-Paul Baird, a seed grant from the Medical Research Foundation of Oregon to Steven James St. John, and an Alpha Delta Phi Award to Eric Anh-Nhat Nguyen. We thank Lee Hallagan, Leila Kalmbach, James McCollum, and Lindsay Pour for expert technical assistance.

Correspondence concerning this article should be addressed to JohnPaul Baird, Department of Psychology, Amherst College, Amherst, MA 01002. E-mail: jpbaird@amherst.edu hedonic evaluation of the tastant. For example, humans who develop a CTA after nausea not only minimize ingestion of the conditioned tastant but also report an acquired dislike for it (Pelchat \& Rozin, 1982). In addition, intake measurements cannot distinguish whether CTA-blocking treatments selectively disrupt particular stages of the CTA learning sequence. A given manipulation may disrupt taste or visceral sensation, the ability to integrate taste and visceral information, and/or the ability to consolidate a CTA into or recall it from long-term memory (Spector, Breslin, \& Grill, 1988). Disruption at any point in this sequence blocks CTA learning as assessed through intake measures.

To address some of these problems, Grill and colleagues (Berridge, Grill, \& Norgren, 1981; Pelchat, Grill, Rozin, \& Jacobs, 1983) used a videographic analysis of orofacial ingestion and rejection responses (taste reactivity) to brief intraoral sucrose infusions before and after CTA formation. They determined that CTA shifted the profile of sucrose taste reactivity from a pattern of uniformly ingestive acts to a mixture of ingestion and rejection orofacial movements comparable to quinine hydrochloride (QHCl). Spector et al. (1988) adapted this approach to dissociate the conditioned and unconditioned components of a CTA. They sampled the formation of a CTA through analysis of sucrose taste reactivity responses every $5 \mathrm{~min}$ after $\mathrm{LiCl}$ injection. They observed significantly more rejection and fewer ingestion responses 15-30 min after $\mathrm{LiCl}$ injection. However, no effect was observed if a 20-min delay was interposed between $\mathrm{LiCl}$ injection and the first sucrose infusion, which indicates that the changes in sucrose taste reactivity were due to associative conditioning rather than to a general effect of malaise. Eckel and Ossenkopp (1996) also failed to observe an unconditioned $\mathrm{LiCl}$ effect in a later replication 
of this study. Spector et al. (1988) speculated that the failure to observe unconditioned effects could have been related to the limited number of measures used (ingestion vs. rejection). Others have suggested that the intraoral taste reactivity test is a forcedchoice and time-limited sampling procedure that does not accommodate appetitive behaviors (e.g., approaching or withdrawing from the drinking spout), through which treatment effects may also be expressed (Kent, Cross-Mellor, Kavaliers, \& Ossenkopp, 2002; Wolgin \& Wade, 1990; see also Seeley, Payne, \& Woods, 1995).

In the present study we use licking microstructure analysis to provide a more detailed assay of CTA formation, generalization, and extinction. In this paradigm the temporal distribution of continuous licking from a spout is used to provide several measures of meal structure. Considerable research shows that some microstructural measures vary as a function of the orosensory or visceral feedback signals that control food intake. For example, under constant environmental conditions, the initial rate of ingestion and average size of bursts of licking tend to vary in a positive, monotonic fashion with increases in the concentration of a normally accepted tastant (e.g., sucrose), whereas meal duration and the number of bursts tend to decrease as a function of caloric feedback from the gut (e.g., Davis \& Perez, 1993; Davis \& Smith, 1992; Eisen, Davis, Rauhofer, \& Smith, 2001; Spector, Klumpp, \& Kaplan, 1998).

The continuous sampling and temporal precision (millisecond resolution) of microstructural analysis provides an ideal opportunity to evaluate the formation of a CTA. To measure CTA formation in real time, we allowed rats to drink $0.12 \mathrm{M} \mathrm{LiCl}$, which represents a naturalistic model of CTA formation under conditions of toxin ingestion. We hypothesized that CTA formation would shift the pattern of microstructural responses from one characteristic of responses to palatable tastants to a pattern comparable to the profile of microstructural responses seen in response to aversive tastants, specifically QHCl (Berridge et al., 1981; Spector et al., 1988; Spector \& St. John, 1998).

We also sought to build on the work of Spector et al. (1988) to distinguish associative from unconditioned effects in CTA processing. In the present study we use another measure of association-generalization. CTAs formed from $\mathrm{LiCl}$ ingestion generalize fully to sodium chloride ( $\mathrm{NaCl}$; Loy \& Hall, 2002; Nachman, 1963b). Therefore, we combined the microstructural analysis with a taste generalization paradigm that exploits the gustatory similarities between $\mathrm{LiCl}$ and $\mathrm{NaCl}$ by offering rats $\mathrm{NaCl}$ on test trials subsequent to $\mathrm{LiCl}$ ingestion. Differences in the microstructure of the generalized response may help to identify associative aspects of the CTA. Further, a detailed analysis of licking throughout the entire meal may be sufficiently sensitive to measure possible unconditioned effects of $\mathrm{LiCl}$ on licking. Finally, in Experiment 2 we developed a rapid generalization test to further dissociate associative and unconditioned effects and to begin to explore a temporal threshold for CTA formation.

\section{Experiment 1}

\section{Method}

\section{Subjects}

Thirty-two experimentally naive, albino male Sprague-Dawley rats (Charles River, Wilmington, MA), weighing $208 \pm 4 \mathrm{~g}$ (range $=163$ to
$239 \mathrm{~g}$ ) at the start of the experiment, were tested. Rats were individually housed in Plexiglas cages $(47 \mathrm{~cm} \times 26 \mathrm{~cm} \times 20.5 \mathrm{~cm})$ in a temperaturecontrolled room on a 12-hr light-dark cycle (lights on at 0700). Rats had ad-lib access to water and food (Purina Lab Chow No. 5001, Purina Mills, St. Louis, Missouri) in the home cage prior to testing. Body weight was monitored throughout the experiment.

\section{Apparatus}

Behavioral testing was conducted via a lickometer (DiLog Instruments, Tallahassee, FL) in a separate test room. The lickometer was electronically interfaced to a computer and eight opaque plastic cages $(47 \mathrm{~cm} \times 26 \mathrm{~cm} \times$ $20.5 \mathrm{~cm}$ ). A $28 \mathrm{~mm} \times 8 \mathrm{~mm}$ slot horizontally centered on the cage face 7 $\mathrm{cm}$ above the floor allowed rats to access a single drinking spout attached to an inverted 70-ml glass bottle. Tongue contacts with the spout completed a circuit that passed an imperceptible current (less than $50 \mu \mathrm{A}$ ) through the rat, which allowed the computer to record the time of each lick with 1-ms resolution. Files for each test session for each rat were saved for off-line analysis.

\section{Procedure}

Rats were maintained on a $23.75-\mathrm{hr}$ schedule of water restriction throughout testing. Rats received 15-min fluid access in the test cages every day $2 \mathrm{hr}$ after lights were turned on. Bottles were rinsed and filled prior to each session and were weighed to the nearest $0.1 \mathrm{~g}$ before and after the session to determine fluid intake. All rats were habituated to the test apparatus with 3 consecutive days of access to distilled water in the test cages. For each experiment, habituation was immediately followed by a 6-day acquisition phase and a 6-day test phase. For each phase, rats had access to a test tastant on Days 1, 3, and 5 (taste trials) and access to distilled water on Days 2, 4, and 6 (water repletion days). Rats were able to gain body weight in this paradigm. By the last day of testing, rats in groups that had received $\mathrm{LiCl}$ weighed significantly more (7\% increase) than their pretest body weight, $t(15)=2.57, p<.02$.

Experiment 1 consists of three separate experiments. Rats were randomly assigned to either a control group or a lithium group in each experiment. The lithium groups received $0.12 \mathrm{M} \mathrm{LiCl}$ on Days 1, 3, and 5 of the acquisition phase (three $\mathrm{LiCl}$ trials). In the test phase they were offered $0.12 \mathrm{M} \mathrm{NaCl}, 0.24 \mathrm{M} \mathrm{NaCl}$, or $0.12 \mathrm{M}$ sucrose on Days 1,3 , and 5 (see Table 1). The control groups received $0.12 \mathrm{M} \mathrm{NaCl}, 0.24 \mathrm{M} \mathrm{NaCl}$, or $0.12 \mathrm{M}$ sucrose concentrations during taste test days in both the acquisition and the test phases of the experiment; they never received $\mathrm{LiCl}$. Sucrose was chosen as a normally preferred tastant that is qualitatively distinct from $\mathrm{NaCl}$. Reduced sucrose intake would suggest a contribution of unconditioned effects (i.e., ongoing nausea) on behavior. No effect on sucrose intake would indicate that $\mathrm{NaCl}$ intake reduction after $\mathrm{LiCl}$ should be ascribed to associative effects (Lasiter, 1985).

Table 1

Experiment 1: Summary of conditions

\begin{tabular}{cll}
\hline Group & $\begin{array}{c}\text { Acquisition phase } \\
\text { Trials 1-3 }\end{array}$ & $\begin{array}{c}\text { Test phase } \\
\text { Trials 1-3 }\end{array}$ \\
\hline $1 \mathrm{~A}(n=8)$ & $0.12 \mathrm{M} \mathrm{NaCl}$ & $0.12 \mathrm{M} \mathrm{NaCl}$ \\
$1 \mathrm{~B}(n=8)$ & $0.12 \mathrm{M} \mathrm{LiCl}$ & $0.12 \mathrm{M} \mathrm{NaCl}$ \\
$2 \mathrm{~A}(n=4)$ & $0.24 \mathrm{M} \mathrm{NaCl}$ & $0.24 \mathrm{M} \mathrm{NaCl}$ \\
$2 \mathrm{~B}(n=4)$ & $0.12 \mathrm{M} \mathrm{LiCl}$ & $0.24 \mathrm{M} \mathrm{NaCl}$ \\
3A $(n=4)$ & $0.12 \mathrm{M} \mathrm{sucrose}$ & $0.12 \mathrm{M}$ sucrose \\
3B $(n=4)$ & $0.12 \mathrm{M} \mathrm{LiCl}$ & $0.12 \mathrm{M}$ sucrose \\
\hline
\end{tabular}

Note. Each acquisition and test phase trial was followed by 1 day of 15 -min access to distilled water. $\mathrm{NaCl}=$ sodium chloride; $\mathrm{LiCl}=$ lithium chloride. 


\section{Data Analysis}

We divided total session intake (grams) by the specific gravity of the tastant to convert weight to volume (milliliters) and then divided it by the total number of licks in the session to yield the lick volume (microliters). We calculated meal size (milliliters) by multiplying the number of licks in the meal (first lick of the first burst to last lick of the last burst; Spector \& St. John, 1998) by the average lick volume for that session. Meal duration (minutes) was defined as the session time of the last lick in the meal minus the session time of the first lick in the meal. Average ingestion rate (licks per second) was calculated as the number of licks in the meal divided by meal duration in seconds.

The temporal distribution of licking was analyzed via a variety of custom-made programs (Baird, Grill, \& Kaplan, 1999; Kaplan, Baird, \& Grill, 2001). A licking burst was defined as two or more consecutive licks with no interlick interval (ILI) equal to or exceeding $1 \mathrm{~s}$. Thus, pauses greater than or equal to $1 \mathrm{~s}$ determined burst termination (Spector et al., 1998). We calculated burst duration (seconds) by subtracting the session time of the first lick in the burst from the time of the last lick in that burst. Burst size was calculated as the number of licks in each burst. To minimize artifact registrations due to nonlingual spout contacts, we defined meal onset as the first lick of the first burst containing at least three licks. Latency was defined as the time between placement of the rat into the test cage and the onset of the first burst of licking. Initial lick rate was the number of licks in the 1st min of the meal.

ILIs were analyzed in several ways. We determined the average withinburst ILI (milliseconds) by averaging all ILIs less than $1 \mathrm{~s}$. Because more than $95 \%$ of all ILIs in a meal are less than $250 \mathrm{~ms}$ and are normally distributed below this cutoff (see Davis, 1996, for a discussion), we also determined the average of ILIs less than $250 \mathrm{~ms}$ (Spector \& St. John, 1998). Because a second distribution of ILIs with a mode averaging twice (about $320 \mathrm{~ms}$ ) the principal mode of the ILI distribution (about $160 \mathrm{~ms}$ ) is also commonly observed (see Davis, 1996; Spector et al., 1998; Spector \& St. John, 1998), we evaluated the distribution of ILIs from 250 to 499 ms. Finally, we analyzed ILIs ranging from 500 to $999 \mathrm{~ms}$ to complete analysis for the entire ILI distribution within bursts.

Pauses were defined as ILIs greater than or equal to $1 \mathrm{~s}$. The mean pause duration (seconds) was determined as the meal duration minus the cumulative duration of bursts in the meal, divided by the number of meal pauses (number of bursts minus one). Percentage of pause duration for the meal was the cumulative time of all pauses (ILIs greater than or equal to $1 \mathrm{~s}$ ) divided by the meal duration, multiplied by 100 . The pause ratio was determined as the number of pauses divided by the number of ILIs in the meal (number of licks in the meal minus one). We also evaluated the frequency distribution of pauses by sorting them into bins of various durations.

To measure variations in ingestion pattern over the course of the meal, we analyzed the number of licks for each minute of each test session. In addition, bursts for each test meal were serially ordered and divided into thirds according to the method of Spector and St. John (1998). Average burst size, pause duration, and lick rate were then compared for each serial third.

\section{Results and Discussion}

\section{CTA Acquisition}

LiCl Trials 1-3. To assess CTA formation, we combined acquisition phase data ( $\mathrm{LiCl}$ Trials $1-3)$ for the 16 rats exposed to $\mathrm{LiCl}$ across the three experiments (Groups 1B, 2B, and 3B) and assessed the data using a one-way repeated-measures analysis of variance (ANOVA). All reported significance values for post hoc tests were corrected for multiple comparisons (Bonferroni method).

$\mathrm{LiCl}$ ingestion was markedly affected by repeated $\mathrm{LiCl}$ exposure. Intake on $\mathrm{LiCl}$ Trials 2 and 3 was significantly lower than on Trial $1, F(2,30)=44.93, p<.001$ (see Figure 1 ), indicating a potent CTA. Post hoc comparisons demonstrated that intake on $\mathrm{LiCl}$ Trials 2 and 3 did not differ from each other (all $p \mathrm{~s}>.12$ ). For all subsequent analyses of these data, when a main effect was observed, post hoc comparisons showed that differences were between responses on $\mathrm{LiCl}$ Trial 1 and responses on $\mathrm{LiCl}$ Trials 2 and 3, with no difference between Trials 2 and 3. Thus, only the main effects are reported below.

Although intake was suppressed by more than $85 \%$, there was no overall difference in meal duration across test trials, which indicates that rats with a CTA expressed a sustained but very slow average rate of ingestion of 0.59 licks/s on Trials 2 and 3, almost four times slower than the rate observed on Trial 1 (2.10 licks/s), $F(2,30)=19.93, p<.001$.

An aversion associated with the taste of $\mathrm{LiCl}$ was clearly indicated by the potent decline in the number of licks in the 1st min,

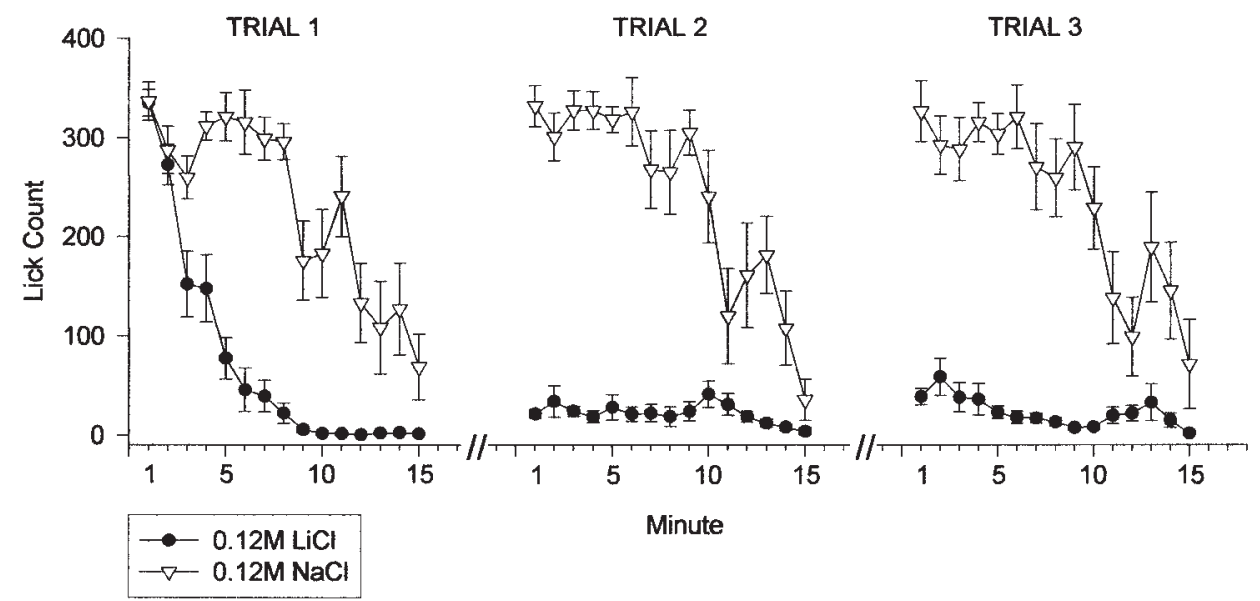

Figure 1. Mean (plus or minus standard error) lick rates (licks per minute) for rats ingesting $0.12 \mathrm{M}$ lithium chloride $(\mathrm{LiCl} ; n=8)$ or $0.12 \mathrm{M}$ sodium chloride $(\mathrm{NaCl} ; n=8)$. 
$F(2,30)=480.71, p<.001$, on LiCl Trials 2 and 3 (see Figure 1). Although both intake and initial lick rate declined considerably, the number of bursts in $\mathrm{LiCl}$ meals was increased by $60 \%$ on Trials 2 and $3, F(2,30)=3.64, p=.02$. The average size of bursts was reduced almost sevenfold, from a mean of $55.82 \pm 10.62$ licks/ burst on Trial 1 to $8.27 \pm 1.78$ licks/burst and $7.92 \pm 0.87$ licks/burst on Trials 2 and 3, respectively, $F(2,30)=19.76, p<$ .001. Further, the average lick volume was almost halved after $\mathrm{LiCl}$ exposure on Trial 1 , from $6.07 \pm 0.74 \mu \mathrm{L}$ to $3.77 \pm 0.45 \mu \mathrm{L}$ on Trial 2 and $3.54 \pm 0.45 \mu \mathrm{L}$ on Trial $3, F(2,30)=5.84, p=$ 01 .

Overall, on the second and third $\mathrm{LiCl}$ trials, the rats licked the spout in a more stop-and-go fashion: Bursts of licking were short but persisted throughout the session. A shortening of bursts with no change in meal duration might lead to the inference that pauses grew longer; however, the mean pause duration did not vary significantly across $\mathrm{LiCl}$ trials, $F(2,30)=0.98, p=.39$. Rather, rats expressed many more pauses, as indicated by the doubling of burst count (pause count $=$ number of bursts minus one). On Trial 1 the average pause was twice as long as each burst; on Trials 2 and 3 pauses $(M=22.17 \pm 4.04 \mathrm{~s})$ were more than 10 times longer than the average burst of licking $(M=1.62 \pm 0.21 \mathrm{~s})$. Thus, the proportion of meal duration spent in pauses between bursts was increased from $67 \%$ on Trial 1 to a mean of $90 \%$ on Trials 2 and $3, F(2,30)=27.32, p<.001$.

The formation of a CTA slowed the average rate of licking within bursts considerably, from 6.17 licks/s to 3.60 licks/s (see Figure 2A), as indicated by a significant increase in the average ILI (1-999 ms range) of licks within bursts on Trials 2 and 3, $F(2$, $30)=29.55, p<.001$. Because the vast majority of ILIs in meals ranged from 1 to $249 \mathrm{~ms}$ (93\% of ILIs on Trial 1; see also Method section), we anticipated that the average duration of ILIs in this range would be greatly increased. However, there was no difference across $\mathrm{LiCl}$ trials, $F(2,30)=0.79, p=.46$. We therefore extended the analysis to the remaining ranges of ILIs within bursts and were further surprised to find little effect: The mean duration of ILIs ranging from 250 to $499 \mathrm{~ms}$ was not significantly changed, $F(2,30)=1.45, p=.25$, and the mean duration of ILIs ranging from 500 to $999 \mathrm{~ms}$ was significantly prolonged by only $39 \mathrm{~ms}$, $F(2,30)=6.19, p<.006$ (see Figure 2A), a 6\% increase insufficient to account for the near halving of lick rate within bursts. We therefore hypothesized that rats were expressing very

\section{A. Lick rate and interlick intervals:}
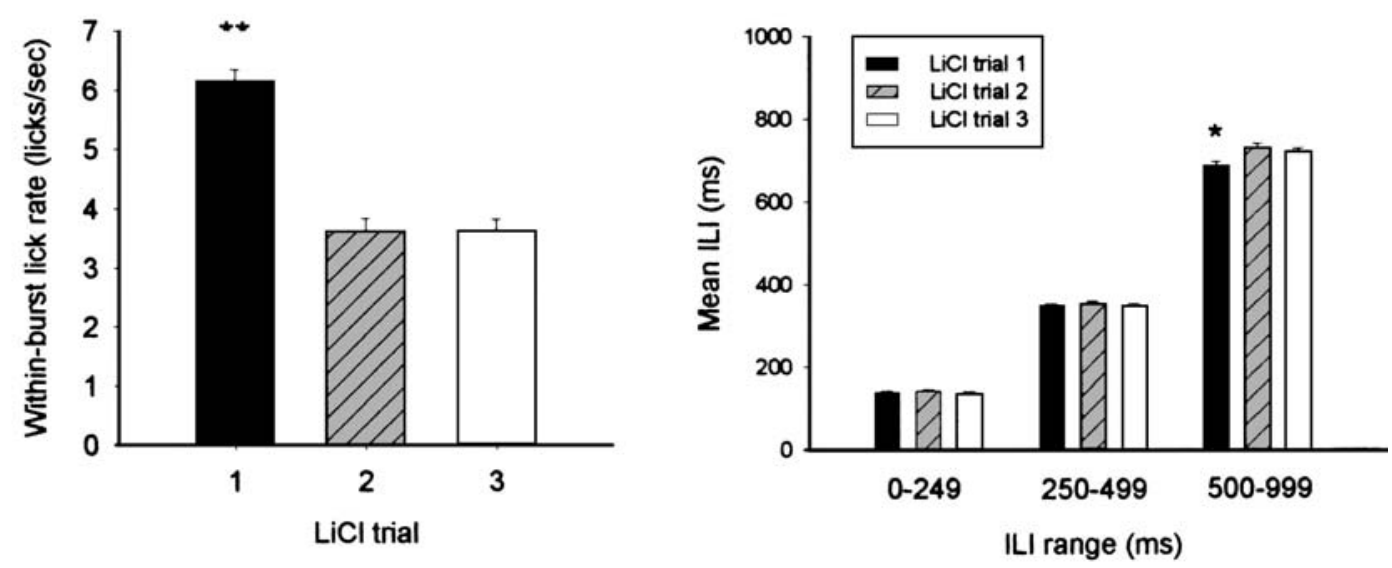

\section{B. Proportion of ILIs within bursts:}
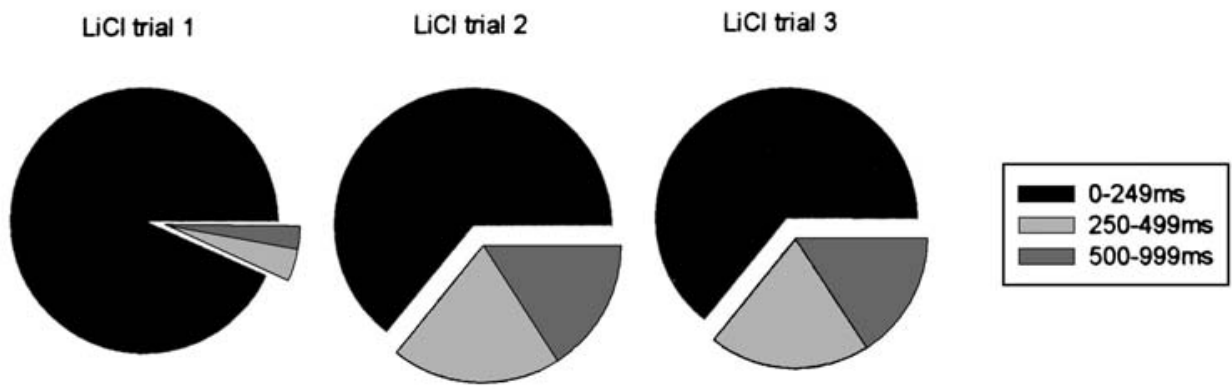

Figure 2. Comparison of within-burst licking measures for rats drinking $0.12 \mathrm{M}$ lithium chloride ( $\mathrm{LiCl})$ across acquisition trials. Figure 2A: Mean (plus standard error) rate of licking within bursts was significantly (more than $40 \%$ ) slower on $\mathrm{LiCl}$ Trials 2 and 3 (left panel). However, this rate reduction was not principally due to increases in the mean duration of interlick intervals (ILIs) for three distribution ranges within the burst (right panel). Figure 2B: The reduction of within-burst lick rate was largely due to a significant increase in the proportion of longer ILIs (at least $250 \mathrm{~ms}$ ) within bursts. ${ }^{*} p<.006 .{ }^{* *} p<.001$. 
brief hesitations at the spout that would be reflected by a proportional increase in longer ILIs within bursts (see Figure 2B). Indeed, the proportion of ILIs within bursts ranging 0-249 ms dropped from a mean of $93 \%$ on Trial 1 to $64 \%$ on LiCl Trials 2 and 3, F(2, $30)=32.61, p<.001$. Accordingly, the proportion of ILIs in the $250-499 \mathrm{~ms}$ range increased from $3 \%$ on Trial 1 to a mean of $19 \%$ on Trials 2 and $3, F(2,30)=29.67, p<.001$, and ILIs ranging 500-999 ms respectively increased from $3 \%$ to $17 \%, F(2,30)=$ 26.20, $p<.001$ (see Figure 2B).

Comparison with $\mathrm{QHCl}$ licking microstructure. Although clear shifts in the microstructural responses to $\mathrm{LiCl}$ were evident in the transition from Trial 1 to Trials 2 and 3, it is possible that the effect magnitudes were reduced because of formation of the CTA during the first trial itself (see below). We therefore compared microstructural responses to $\mathrm{LiCl}$ on Trial 3 with those for water on the habituation day preceding the first $\mathrm{LiCl}$ trial, using paired $t$ tests. This analysis also permitted comparison of the $\mathrm{LiCl}$ microstructure with the microstructure for bitter $\mathrm{QHCl}$ reported previously (Hsiao \& Fan, 1993; Spector \& St. John, 1998). In these studies, intact rats ingesting $\mathrm{QHCl}$ exhibited, relative to licking for water, decreases in intake, lick volume, burst size, and pause duration, whereas meal duration, burst count, and intraburst lick rate were increased (see Table 2). All of these trends, except for an effect on meal duration, were replicated for rats drinking $\mathrm{LiCl}$ (see Table 2). These results strongly suggest that the rats' hedonic evaluation of $\mathrm{LiCl}$ after CTA formation closely resembles that for bitter QHCl.

As noted, $\mathrm{LiCl}$ increased pause counts; however, this increase was not evenly distributed. Relative to water, the proportion of pauses ranging $1-2 \mathrm{~s}$ increased, $t(15)=-2.76, p<.02$, and those in the $5-10$ s range decreased, $t(15)=-2.26, p=.04$. Comparisons of other pause ranges revealed no significant differences $(p s>.10)$.

Dynamics of rapid CTA formation during LiCl Trial 1. Although rats exhibited clear differences between their responses to $\mathrm{LiCl}$ on Trial 1 and their responses on Trials 2 and 3, we hypothesized that a CTA was formed during $\mathrm{LiCl}$ Trial 1. We compared Acquisition Trial 1 meal progress measures (minute by minute and in meal thirds) for Group $1 \mathrm{~A}$ (which received $0.12 \mathrm{M} \mathrm{NaCl}$ ) and Group 1B (which received $0.12 \mathrm{M} \mathrm{LiCl}$ ), using a mixed factors two-way ANOVA (Group $\times$ Meal Minute) and between-subjects $t$ tests.

Initially, behavioral responses to $\mathrm{LiCl}$ and $\mathrm{NaCl}$ across both groups were indistinguishable. There was no statistically significant difference in the initial rate (1st min) of licking for either 0.12 $\mathrm{M} \mathrm{NaCl}$ or $0.12 \mathrm{M} \mathrm{LiCl}$ on the first acquisition trial, $t(14)=0.34$, $p=.74$ (see Figure 1). Further, comparison of meals divided serially into thirds by bursts revealed that, for both groups, the mean burst sizes, pause durations, and lick rates in the first third of the meal were almost identical (see Figure 3). However, as meals progressed, significant differences between the two groups began to emerge.

Nachman (1963a) showed that rats ingesting $\mathrm{LiCl}$ exhibited almost completely suppressed intake within $8 \mathrm{~min}$ of $\mathrm{LiCl}$ intake onset. We observed a virtually identical outcome. Relative to rats ingesting $0.12 \mathrm{M} \mathrm{NaCl}$, the ingestion of $0.12 \mathrm{M} \mathrm{LiCl}$ was significantly slower by the 4 th $\min$ (see Figure 1), as indicated by a significant interaction term, $F(14,196)=5.51, p<.001$, and post

Table 2

Comparison of LiCl Licking Microstructure With Reported QHCl Licking Microstructure

\begin{tabular}{|c|c|c|c|c|c|c|c|c|c|}
\hline \multirow[b]{2}{*}{ Measure } & \multicolumn{2}{|c|}{ Baseline $\mathrm{dH}_{2} \mathrm{O}$} & \multicolumn{2}{|c|}{$\mathrm{LiCl}$ Trial 3} & \multirow[b]{2}{*}{$t(15)$} & \multirow[b]{2}{*}{$p$} & \multirow[b]{2}{*}{ Effect size } & \multirow{2}{*}{$\begin{array}{c}0.2 \mathrm{mM} \mathrm{QHCl} \\
\text { vs. } \mathrm{dH}_{2} \mathrm{O}^{\mathrm{a}}\end{array}$} & \multirow{2}{*}{$\begin{array}{l}0.25 \mathrm{mM} \mathrm{QHCl} \\
\text { vs. } \mathrm{dH}_{2} 0^{\mathrm{b}}\end{array}$} \\
\hline & $M$ & $S E$ & $M$ & $S E$ & & & & & \\
\hline Intake $(\mathrm{ml})$ & 13.70 & 0.67 & 1.22 & 0.25 & -29.62 & .00 & $\downarrow 91 \%$ & $\downarrow 74 \%$ & $\downarrow$ \\
\hline Lick count & 2641.25 & 104.49 & 349.25 & 52.04 & -21.66 & .00 & $87 \%$ & $56 \%$ & $\downarrow$ \\
\hline Lick volume $(\mu 1)$ & 5.21 & 0.20 & 3.88 & 0.44 & -2.42 & .03 & $\downarrow 26 \%$ & $\downarrow 38 \%$ & $\downarrow$ \\
\hline Meal duration (min) & 12.78 & 0.43 & 11.35 & 1.00 & -1.30 & .21 & $\downarrow 11 \%$ & $\uparrow 37 \%$ & \\
\hline Ingestion rate (licks/s) & 3.46 & 0.12 & 0.75 & 0.25 & -12.01 & .00 & $\downarrow 78 \%$ & & \\
\hline Initial lick rate & 354.75 & 11.75 & 38.88 & 8.48 & -29.62 & .00 & $89 \%$ & $\downarrow 52 \%$ & \\
\hline Burst count & 20.75 & 2.51 & 42.19 & 5.40 & 3.64 & .00 & $\uparrow 103 \%$ & $\uparrow 378 \%$ & $\uparrow$ \\
\hline Mean burst size (licks) & 161.40 & 23.40 & 7.92 & 0.86 & 6.72 & .00 & $95 \%$ & $\downarrow 87 \%$ & $\downarrow$ \\
\hline Mean burst duration (s) & 23.83 & 3.70 & 1.66 & 0.16 & 6.16 & .00 & $\downarrow 93 \%$ & & \\
\hline Latency (s) & 5.91 & 2.58 & 90.55 & 42.99 & 2.20 & .06 & $\uparrow 1,400 \%$ & & \\
\hline Pause time $(\%)$ & 49.72 & 1.89 & 89.44 & 1.28 & 22.61 & .00 & $\uparrow 79 \%$ & & \\
\hline Mean pause duration (s) & 25.48 & 3.80 & 18.63 & 2.49 & 1.52 & .15 & $27 \%$ & $\downarrow 52 \%$ & \\
\hline Pause ratio & 0.74 & 0.09 & 13.59 & 1.18 & 10.83 & .00 & $\uparrow 1,686$ & & $\uparrow$ \\
\hline \multicolumn{10}{|l|}{ ILI range groups } \\
\hline $0-999 \mathrm{~ms}$ & 146.40 & 2.64 & 275.59 & 14.26 & 8.17 & .00 & $\uparrow 88 \%$ & & \\
\hline $0-249 \mathrm{~ms}$ & 142.76 & 2.58 & 136.97 & 2.13 & -1.85 & .08 & \ $4.1 \%$ & $\downarrow 3.3 \%$ & No significant change $\mathrm{e}^{\mathrm{c}}$ \\
\hline $250-499 \mathrm{~ms}$ & 335.37 & 4.76 & 347.09 & 3.22 & 1.96 & .08 & $\uparrow 3.5 \%$ & & \\
\hline $500-999 \mathrm{~ms}$ & 698.62 & 12.57 & 720.44 & 6.87 & 1.42 & .17 & $\uparrow 3.1 \%$ & & \\
\hline \multicolumn{10}{|l|}{$\begin{array}{l}\text { Range proportions } \\
\text { (\% ILIs in burst })\end{array}$} \\
\hline $0-249 \mathrm{~ms}$ & 98.91 & 0.65 & 63.97 & 3.63 & -9.61 & .00 & $\downarrow 35 \%$ & & \\
\hline $250-499 \mathrm{~ms}$ & 0.66 & 0.11 & 19.11 & 2.17 & 8.54 & .00 & $\uparrow 2,790 \%$ & & \\
\hline $500-999 \mathrm{~ms}$ & 0.43 & 0.06 & 16.92 & 1.97 & 8.31 & .00 & $\uparrow 3,862 \%$ & & \\
\hline
\end{tabular}

Note. Bold font indicates that $p$ met the criterion for statistical significance, which was set at $p \leq .05$. LiCl $=$ lithium chloride; QHCl $=$ quinine hydrochloride; $\mathrm{dH}_{2} \mathrm{O}=$ distilled water; ILI = interlick interval.

${ }^{\mathrm{a}}$ From Spector and St. John (1998). ${ }^{\mathrm{b}}$ From Hsiao and Fan (1993). ${ }^{\mathrm{c}}$ ILIs $<230$ ms were evaluated. 

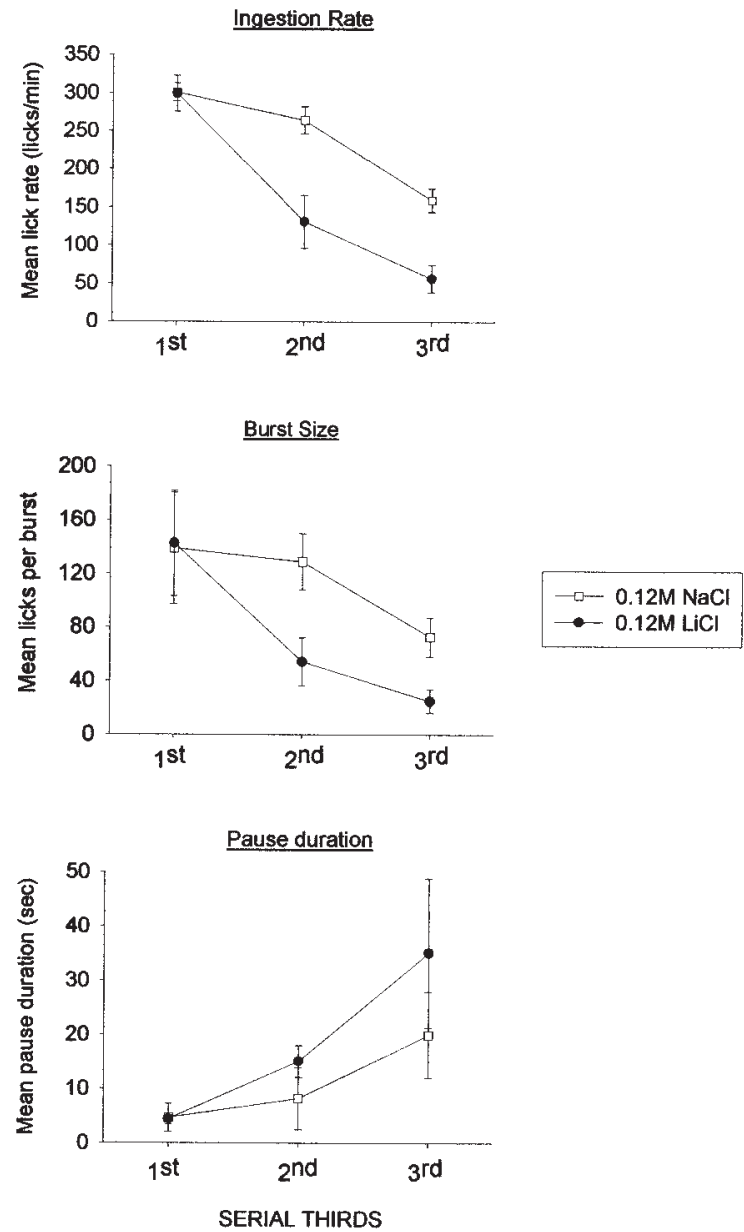

Figure 3. Bursts and pauses for each rat were serially ordered for the first trial for $0.12 \mathrm{M}$ lithium chloride $(\mathrm{LiCl})$ or $0.12 \mathrm{M}$ sodium chloride $(\mathrm{NaCl})$ ingestion in Groups 1A and 1B and broken down into roughly equal one-third segments. Mean (plus or minus standard error) ingestion rate (licks per minute), mean burst size (licks per burst), and mean pause duration (seconds) associated with each segment are presented. Burst size and ingestion rate measures were virtually identical in the first third of the meal: size, $t(14)=0.06, p=.95$; rate, $t(14)=0.49, p=.64$. As meals progressed, burst size for $\mathrm{LiCl}$ was significantly reduced for the remaining two thirds: middle third, $t(14)=2.70, p<.02$; last third, $t(14)=2.82, p<$ .02. Ingestion rate was significantly reduced for $\mathrm{LiCl}$ in the middle third, $t(14)=4.83, p=.001$, but not the last third $(p=.09)$. No significant differences were observed for mean pause duration $(p s>.21)$.

hoc comparisons $(p s<.02)$. In addition, as $\mathrm{LiCl}$ meals progressed, rats expressed significantly smaller bursts in the second and last thirds of the meal relative to rats ingesting $\mathrm{NaCl}$ (see the legend of Figure 3 for statistics).

\section{CTA Generalization}

To assess generalization to $\mathrm{NaCl}$, we evaluated two planned comparisons for each behavioral measure. The first was a pairedsamples $t$ test to evaluate carryover from $\mathrm{LiCl}$ Trial 3 to $\mathrm{NaCl} /$ sucrose Trial 1, within each of the LiCl-exposed groups (Groups $1 \mathrm{~B}, 2 \mathrm{~B}$, and 3B). A second independent-samples $t$ test was used to compare responses of the $\mathrm{LiCl}$ groups $(1 \mathrm{~B}, 2 \mathrm{~B}$, and $3 \mathrm{~B})$ on $\mathrm{NaCl}$ Trial 1 (as above) with responses on the matching $\mathrm{NaCl} /$ sucrose test day (Test Trial 1) of the control groups (1A, 2A, and $3 \mathrm{~A})$, which received only $\mathrm{NaCl}$ or sucrose in the three preceding trials of the acquisition phase. Means (plus or minus standard error) and statistics for these comparisons are reported in Tables 3, 4, and 5.

Overall, $\mathrm{LiCl}$ aversion strongly generalized to $0.12 \mathrm{M}$ and 0.24 $\mathrm{M} \mathrm{NaCl}$ (see Tables 3 and 4) but not to sucrose (see Table 5). $\mathrm{NaCl}$ intakes after $\mathrm{LiCl}$ exposure were markedly lower $(75 \%$ for $0.12 \mathrm{M}$ $\mathrm{NaCl}$ and $81 \%$ for $0.24 \mathrm{M} \mathrm{NaCl}$ ) than the respective control group $\mathrm{NaCl}$ intakes (see Figures 4 and 5 and Tables 3 and 4). Initial lick rates were comparably slow between $\mathrm{LiCl}$ Trial 3 and $\mathrm{NaCl}$ Trial 1 at both $\mathrm{NaCl}$ concentrations and significantly slower relative to $\mathrm{NaCl}$ control groups (see Tables 3 and 4, Figures 4 and 5). The suppressed initial rate of licking for $\mathrm{NaCl}$ was not likely due to neophobia, because the initial lick rate for $0.12 \mathrm{M} \mathrm{NaCl}$ in the control group (1A) between Acquisition Trial 1 and Test Trial 1 was not significantly different, $t(7)=-0.61, p=.56$ (see also Figure 4). Thus, initial rate measures suggest a full generalization of $\mathrm{LiCl}$ CTA to $\mathrm{NaCl}$.

The pattern of licking for $\mathrm{NaCl}$ after $\mathrm{LiCl}$ exposure resembled that for $\mathrm{LiCl}$. Figure 5 shows that most measures of $\mathrm{NaCl}$ licking after $\mathrm{LiCl}$ exposure resembled the profile of licking responses for $\mathrm{LiCl}$ much more than they resembled the profile of licking for the same $\mathrm{NaCl}$ concentration by rats never exposed to $\mathrm{LiCl}$. Relative to rats with no $\mathrm{LiCl}$ experience (Groups 1A and 2A), the licking pattern for $\mathrm{LiCl}$ and conditioned $\mathrm{NaCl}$ was stop-and-go: Bursts were smaller but more numerous, rats spent more session time away from the spout, and licking within bursts was slower (see Tables 3 and 4). Mean burst sizes and burst durations were much smaller for $\mathrm{NaCl}$ after $\mathrm{LiCl}$ than for the $\mathrm{NaCl}$ control groups (see Tables 3 and 4, Figure 5), and the proportion of meal duration expressed as pauses was also increased (see Tables 3 and 4, Figure 5).

The slower rate of licking within bursts observed during $\mathrm{LiCl}$ drinking also generalized to $\mathrm{NaCl}$ (Tables 3 and 4). This slowing effect was mostly due to an increase in the proportion of ILIs greater than $249 \mathrm{~ms}$ within bursts, and it significantly generalized to $\mathrm{NaCl}$ (see Tables 3 and 4). Although there was no effect of $\mathrm{LiCl}$ exposure on the average duration of pauses in the meal, there was a significant increase in the relative proportion of pauses falling in the 1-2 s range for both $\mathrm{NaCl}$ concentrations: $0.12 \mathrm{M} \mathrm{NaCl}$, $t(14)=3.07, p<.01 ; 0.24 \mathrm{M} \mathrm{NaCl}, t(6)=2.58, p=.04$. The frequency of pauses for $\mathrm{NaCl}$ after $\mathrm{LiCl}$ in this range was doubled in comparison with $\mathrm{NaCl}$ controls (see Figure 6, only $0.12 \mathrm{M} \mathrm{NaCl}$ shown). Overall, CTA had the effect of selectively increasing the incidence of ILIs ranging from $250 \mathrm{~ms}$ to $2 \mathrm{~s}$.

Finally, the average lick volume was roughly halved by $\mathrm{LiCl}$ exposure (see CTA Acquisition section). This reduction also generalized to both $\mathrm{NaCl}$ concentrations (see Tables 3 and 4, Figures 4 and 5) and also to sucrose (see Table 5).

\section{CTA Extinction}

An independent samples $t$ test was used to assess whether the generalization of CTA to $\mathrm{NaCl}$ Trial 1 was fully extinguished by the third $\mathrm{NaCl}$ trial for whole-meal and microstructural measures. The minute-to-minute lick rate was also compared across test groups (Groups A vs. B) for each test period trial via a two-way 
Table 3

Generalization of $0.12 \mathrm{M} \mathrm{LiCl} \mathrm{CTA} \mathrm{to} 0.12 \mathrm{M} \mathrm{NaCl}$

\begin{tabular}{|c|c|c|c|c|c|c|c|c|c|c|}
\hline \multirow[b]{2}{*}{ Measure } & \multicolumn{2}{|c|}{$\begin{array}{l}\text { (A) Group 1B: } \\
\text { LiCl Trial } 3 \\
\text { (CTA) }\end{array}$} & \multicolumn{2}{|c|}{$\begin{array}{l}\text { (B) Group 1B: } \\
\text { NaCl Test Trial } 1 \\
\text { (generalization) }\end{array}$} & \multicolumn{2}{|c|}{$\begin{array}{l}\text { (C) Group 1A: } \\
\text { NaCl Test Trial } 1 \\
\text { (control) }\end{array}$} & \multicolumn{2}{|c|}{ A vs. B } & \multicolumn{2}{|c|}{ B vs. C } \\
\hline & $M$ & $S E$ & $M$ & $S E$ & $M$ & $S E$ & $t(7)$ & $p$ & $t(14)$ & $p$ \\
\hline Intake (ml) & 0.97 & 0.23 & 4.78 & 1.06 & 24.96 & 0.87 & -3.84 & .01 & -14.72 & .00 \\
\hline Lick count & 361.38 & 156.50 & $1,160.75$ & 229.38 & $3,796.00$ & 108.65 & -3.95 & .01 & -10.38 & .00 \\
\hline Lick volume $(\mu \mathrm{l})$ & 3.11 & 0.39 & 4.07 & 0.25 & 6.61 & 0.80 & -2.15 & .05 & -6.68 & .00 \\
\hline Meal duration (min) & 12.12 & 1.10 & 14.51 & 0.20 & 14.32 & 0.36 & -2.03 & .08 & 0.47 & .64 \\
\hline Ingestion rate (licks/s) & 0.46 & 0.11 & 1.33 & 0.27 & 4.42 & 0.09 & -3.55 & .01 & -10.40 & .00 \\
\hline Initial lick rate & 32.63 & 9.04 & 104.50 & 46.26 & 330.88 & 33.30 & -1.76 & .12 & -3.97 & .00 \\
\hline Burst count & 37.75 & 8.82 & 57.87 & 12.18 & 35.37 & 3.17 & -2.08 & .07 & 1.79 & .10 \\
\hline Mean burst size (licks) & 8.37 & 1.64 & 24.43 & 7.59 & 113.11 & 10.13 & -2.12 & .07 & -7.01 & .00 \\
\hline Mean burst duration (s) & 1.61 & 0.31 & 4.07 & 1.14 & 16.39 & 1.33 & -2.19 & .06 & -7.03 & .00 \\
\hline Latency (s) & 121.19 & 85.25 & 5.79 & 3.43 & 1.98 & 1.04 & 1.35 & .22 & 1.06 & .31 \\
\hline Pause time $(\%)$ & 90.98 & 2.27 & 77.50 & 4.05 & 35.59 & 1.96 & 3.72 & .01 & 9.32 & .00 \\
\hline Mean pause duration (s) & 26.45 & 7.17 & 19.88 & 7.57 & 9.48 & 1.10 & 0.69 & .51 & 1.36 & .19 \\
\hline Pause ratio & 0.15 & 0.03 & 0.07 & 0.02 & 0.01 & 0.00 & 2.78 & .03 & 3.82 & .00 \\
\hline \multicolumn{11}{|l|}{ ILI range groups } \\
\hline 0-999 ms & 256.29 & 20.27 & 207.29 & 17.09 & 146.99 & 3.16 & 1.82 & .11 & 3.47 & .00 \\
\hline $0-249 \mathrm{~ms}$ & 134.70 & 3.45 & 137.99 & 1.89 & 142.71 & 2.38 & -0.91 & .39 & -1.56 & .14 \\
\hline $250-499 \mathrm{~ms}$ & 341.43 & 4.83 & 355.09 & 2.79 & 339.58 & 8.60 & -1.85 & .11 & 1.72 & .11 \\
\hline $500-999 \mathrm{~ms}$ & 712.03 & 11.78 & 725.33 & 11.60 & 679.28 & 13.44 & -0.84 & .43 & 2.59 & .02 \\
\hline \multicolumn{11}{|c|}{ Range proportions (\% ILIs in burst) } \\
\hline $0-249 \mathrm{~ms}$ & 68.15 & 5.36 & 82.30 & 4.34 & 98.64 & 0.36 & -1.98 & .09 & -3.75 & .00 \\
\hline $250-499 \mathrm{~ms}$ & 16.96 & 3.15 & 9.46 & 2.39 & 0.91 & 0.25 & 1.70 & .13 & 3.56 & .00 \\
\hline $500-999 \mathrm{~ms}$ & 14.89 & 3.04 & 8.24 & 2.00 & 0.45 & 0.37 & 1.93 & .10 & 3.89 & .00 \\
\hline
\end{tabular}

Note. Bold font indicates that $p$ met the criterion for statistical significance, which was set at $p \leq .05 . \mathrm{LiCl}=$ lithium chloride; $\mathrm{CTA}=$ conditioned taste aversion; $\mathrm{NaCl}=$ sodium chloride; ILI = interlick interval.

mixed factors ANOVA (Minute $\times$ Group). Only the results for $0.12 \mathrm{M} \mathrm{NaCl}$ are presented. Results for rats tested with $0.24 \mathrm{M}$ $\mathrm{NaCl}$ were comparable, except that some measures fully extinguished with only two extinction trials (e.g., see Figure 4).

On the first $\mathrm{NaCl}$ trial after $\mathrm{LiCl}$, intake, burst size, burst duration, lick volume, intake, intraburst lick rate, initial lick rate, and various pause measures were significantly different from controls (see Table 3; see also Figures 4 and 5). By the third $\mathrm{NaCl}$ trial, almost all of these differences were abolished; only intake and lick volume remained significantly suppressed (see Table 6, Figures 4 and 5). However, even these measures had recovered appreciably (62\% and $49 \%$, respectively) relative to their levels on $\mathrm{NaCl}$ Test Trial 1.

Rapid extinction was also apparent in the rate of licking in each $\mathrm{NaCl}$ trial in the test phase. On Test Trial 1, both main effects were significant-group, $F(1,14)=101.75, p<.0001$; minute, $F(14$, $196)=3.87, p<.01$ - as was the interaction term, $F(14,196)=$ $3.45, p=.02$. Thus, $\mathrm{NaCl}$ ingestion after $\mathrm{LiCl}$ exposure was significantly slower than that for the control group, although the ingestion rates tended to converge at the end of the test (see Figure 7). On the second extinction trial, the initial rates of ingestion were faster than those in the preceding trial, resulting in more parallel although separate ingestion rate curves between both groups. Hence, the interaction term was no longer significant, $F(14$, 196) $=0.86, p=.51$, although both of the main effects were significant: minute, $F(14,196)=5.61, p<.001$; group, $F(1$, $14)=23.40, p<.001$. By the third extinction trial, ingestion rate curves between the two groups were mostly overlapping, which suggests that the CTA was extinguished (see Figure 7). This is supported by the lack of a significant main effect of group on Trial $3, F(1,14)=3.51, p=.082$, and the lack of an interaction term, $F(14,196)=1.58, p=.09$, although a main effect of minute, $F(14,196)=11.16, p<.001$, indicated a gradual decline in ingestion rates.

\section{Experiment 2}

In Experiment 1, rats ingesting $\mathrm{LiCl}$ exhibited a rapid decline in ingestion rate that significantly departed from ingestion of an equimolar concentration of $\mathrm{NaCl}$ by the 4 th min of the test. A CTA was definitely established at some time prior to $\mathrm{LiCl}$ Trial 2, because lick rate was markedly suppressed at the very beginning (1st min) of the second $\mathrm{LiCl}$ trial. We hypothesized that the CTA was formed within the first $8 \mathrm{~min}$ of the first $\mathrm{LiCl}$ trial, the time at which $\mathrm{LiCl}$ licking was suppressed to an almost negligible rate $(22.00 \pm 10.24 \mathrm{licks} / \mathrm{min})$. However, it is also possible that intake suppression at this time was due to malaise rather than associative factors and that the taste-malaise association was made at a later time.

To evaluate this hypothesis, we used an MS-160 Davis Rig (DiLog Instruments, Tallahassee, FL) to rapidly switch tastants offered to rats during a single test trial. In the key experiments, rats were offered $0.12 \mathrm{M} \mathrm{LiCl}$ for $8 \mathrm{~min}$ and then offered a second tastant for another $8 \mathrm{~min}$. If a CTA to the taste of $\mathrm{LiCl}$ is formed during the first $8 \mathrm{~min}$ of $\mathrm{LiCl}$ ingestion, the ingestion rate suppression exhibited during $\mathrm{LiCl}$ exposure should remain suppressed when rats are offered either $0.12 \mathrm{M} \mathrm{LiCl}$ or $\mathrm{NaCl}$ in the second half of the trial but not when they are offered water or $0.12 \mathrm{M}$ sucrose. 
Table 4

Generalization of $0.12 \mathrm{M} \mathrm{LiCl} \mathrm{CTA}$ to $0.24 \mathrm{M} \mathrm{NaCl}$ Intake

\begin{tabular}{|c|c|c|c|c|c|c|c|c|c|c|}
\hline \multirow[b]{2}{*}{ Measure } & \multicolumn{2}{|c|}{$\begin{array}{l}\text { (A) Group 2B: } \\
\text { LiCl Trial } 3 \\
\text { (CTA) }\end{array}$} & \multicolumn{2}{|c|}{$\begin{array}{l}\text { (B) Group 2B: } \\
\text { NaCl Test T1 } \\
\text { (generalization) }\end{array}$} & \multicolumn{2}{|c|}{$\begin{array}{l}\text { (C) Group 2A: } \\
\text { NaCl Test T1 } \\
\text { (control) }\end{array}$} & \multicolumn{2}{|c|}{ A vs. B } & \multicolumn{2}{|c|}{ B vs. C } \\
\hline & $M$ & $S E$ & $M$ & $S E$ & $M$ & $S E$ & $t(3)$ & $p$ & $t(6)$ & $p$ \\
\hline Intake (ml) & 1.44 & 0.39 & 3.39 & 1.01 & 13.41 & 0.72 & -2.07 & .13 & -8.07 & .00 \\
\hline Lick count & 370.50 & 83.40 & 990.25 & 264.74 & $2,404.00$ & 129.54 & -2.26 & .11 & -4.80 & .00 \\
\hline Lick volume $(\mu \mathrm{l})$ & 3.69 & 0.71 & 3.38 & 0.18 & 5.60 & 0.31 & 0.55 & .62 & -6.17 & .00 \\
\hline Meal duration (min) & 13.04 & 1.26 & 14.68 & 0.09 & 13.71 & 0.72 & -1.29 & .29 & 1.33 & .23 \\
\hline Ingestion rate (licks/s) & 0.50 & 0.12 & 1.13 & 0.30 & 2.95 & 0.24 & -2.39 & .10 & -4.72 & .00 \\
\hline Initial lick rate & 32.25 & 10.59 & 38.00 & 12.94 & 246.75 & 80.50 & 0.50 & .65 & -2.56 & .04 \\
\hline Burst count & 54.25 & 9.76 & 54.25 & 9.68 & 26.75 & 4.13 & 0.00 & 1.00 & 2.61 & .04 \\
\hline Mean burst size (licks) & 6.78 & 1.09 & 21.82 & 8.56 & 97.60 & 16.98 & -1.85 & .16 & -3.99 & .01 \\
\hline Mean burst duration (s) & 1.51 & 0.18 & 3.74 & 1.09 & 14.33 & 2.34 & -2.22 & .11 & -4.11 & .01 \\
\hline Latency (s) & 0.98 & 0.57 & 0.12 & 0.05 & 2.76 & 1.79 & 1.45 & .24 & -1.47 & .19 \\
\hline Pause time $(\%)$ & 89.13 & 2.37 & 79.84 & 3.15 & 56.59 & 2.90 & 3.74 & .03 & 5.43 & .00 \\
\hline Mean pause duration (s) & 15.07 & 4.33 & 14.18 & 1.73 & 21.06 & 6.14 & 0.23 & .83 & -1.08 & .32 \\
\hline Pause ratio & 0.16 & 0.02 & 0.07 & 0.03 & 0.01 & 0.00 & 3.59 & .04 & 2.27 & .06 \\
\hline \multicolumn{11}{|l|}{ ILI range groups } \\
\hline $0-999 \mathrm{~ms}$ & 297.23 & 31.48 & 221.43 & 34.63 & 149.89 & 5.19 & 1.62 & .20 & 2.04 & .09 \\
\hline $0-249 \mathrm{~ms}$ & 139.90 & 3.72 & 134.02 & 3.91 & 141.82 & 3.59 & 1.84 & .16 & -1.47 & .19 \\
\hline $250-499 \mathrm{~ms}$ & 349.65 & 4.42 & 361.89 & 3.75 & 345.48 & 10.50 & -2.43 & .09 & 1.47 & .19 \\
\hline $500-999 \mathrm{~ms}$ & 722.88 & 11.90 & 723.60 & 6.83 & 686.63 & 16.18 & -0.05 & .96 & 2.11 & .08 \\
\hline \multicolumn{11}{|c|}{ Range proportions (\% ILIs in burst) } \\
\hline $0-249 \mathrm{~ms}$ & 58.50 & 6.74 & 78.50 & 7.67 & 97.79 & 0.37 & -2.25 & .11 & -2.50 & .05 \\
\hline $250-499 \mathrm{~ms}$ & 22.23 & 2.64 & 10.59 & 3.52 & 1.20 & 0.10 & 5.66 & .01 & 2.66 & .04 \\
\hline $500-999 \mathrm{~ms}$ & 19.26 & 4.65 & 10.91 & 4.32 & 1.01 & 0.31 & 1.20 & .32 & 2.28 & .06 \\
\hline
\end{tabular}

Note. Bold font indicates that $p$ met the criterion for statistical significance, which was set at $p \leq .05$. LiCl $=$ lithium chloride; CTA $=$ conditioned taste aversion; $\mathrm{NaCl}=$ sodium chloride; $\mathrm{ILI}=$ interlick interval.

However, if the behavioral suppression at the 8 th $\min$ is instead or also due to unconditioned malaise, intake should remain suppressed for all four stimuli offered subsequent to $\mathrm{LiCl}$ ingestion.

\section{Method}

\section{Subjects}

Thirty-eight naive, male albino Sprague-Dawley rats (Charles River, Wilmington, MA) weighing $300 \pm 9 \mathrm{~g}$ (range $=223$ to $411 \mathrm{~g}$ ) were subjects of the experiment. Rats were housed individually in cages similar to those used in Experiment 1 in a room where temperature and lighting (12-hr light-dark cycle) were automatically controlled. All manipulations were performed during the lights-on portion of the cycle. Food (Harlan Teklab 8604, Madison, WI) and tap water were available ad libitum except where noted.

\section{Apparatus}

Rats were tested daily in an automated lickometer referred to as the Davis Rig (Davis MS-160, DiLog Instruments, Tallahassee, FL). Unlike the single-bottle lickometer in Experiment 1, the Davis Rig allows the presentation of up to 16 different taste stimuli within a single behavioral session, with a minimum interstimulus interval of $7.5 \mathrm{~s}$ (Rhinehart-Doty, Schumm, Smith, \& Smith, 1994; G. P. Smith, 2001). Rats are placed in a plastic rectangular cage $(30 \mathrm{~cm} \times 14.5 \mathrm{~cm} \times 18 \mathrm{~cm})$ with a wire mesh floor and have access to sipper tubes (when a computer-operated shutter is lifted) via an oval opening centered in the front wall of the test chamber. Licks on the spout are recorded by microcomputer via a circuit similar to that of the lickometer used in Experiment 1.

\section{Procedure}

Following overnight water restriction, rats were habituated to the Davis Rig over four daily sessions and were tested on the 5th day. On Sessions 1 and 2, rats were offered a single 15-min trial of distilled water (the clock began with the first lick). On Sessions 3 and 4, rats were given two 8-min trials of distilled water with two different stimulus bottles housed on a motorized track outside the test chamber. Each 8-min trial began with the rat's first lick. At the end of the first trial (T1), the shutter closed for $7.5 \mathrm{~s}$ while the next sipper tube was positioned. If the rat did not initiate the second trial (T2) within $5 \mathrm{~min}$, the session ended. Stimulus bottles were weighed to the nearest $0.01 \mathrm{~g}$ before and after the session to monitor total intake.

Conditions were identical on the test day, except for the taste stimuli used during $\mathrm{T} 1$ and $\mathrm{T} 2$. In brief, four groups received $0.12 \mathrm{M} \mathrm{LiCl}$ at T1 and then received $\mathrm{LiCl}, \mathrm{NaCl}$, sucrose, or water at $\mathrm{T} 2$ (see Table 7). Two control groups were also tested; one received $\mathrm{NaCl}$ (T1) and water (T2), and the other received $\mathrm{NaCl}$ on both $\mathrm{T} 1$ and $\mathrm{T} 2$. These conditions allowed assessment of behavior toward the conditioned stimulus (CS), a qualitatively similar stimulus, a dissimilar stimulus, and water.

\section{Data Analysis}

To address specific hypotheses, we performed a number of planned contrasts. For each test group, we used repeated-measures ANOVA to compare differences across the two halves of the test session (T1 vs. T2). To ensure stable $\mathrm{LiCl}$ responses across groups, we used a one-way between-subjects ANOVA to compare T1 measures for groups that were first exposed to $\mathrm{LiCl}$. These four groups were then pooled for a $t$ test comparison against the $\mathrm{T} 1$ measures for the $\mathrm{NaCl}-\mathrm{NaCl}$ group to provide a $\mathrm{LiCl}-\mathrm{NaCl}$ comparison. To evaluate the relative effects of $\mathrm{T} 1 \mathrm{LiCl}$ 
Table 5

Comparison of $0.12 \mathrm{M} \mathrm{LiCl}$ With $0.12 \mathrm{M}$ Sucrose

\begin{tabular}{|c|c|c|c|c|c|c|c|c|c|c|}
\hline \multirow[b]{2}{*}{ Measure } & \multicolumn{2}{|c|}{$\begin{array}{l}\text { (A) Group 3B: } \\
\text { LiCl Trial } 3 \\
\text { (CTA) }\end{array}$} & \multicolumn{2}{|c|}{$\begin{array}{l}\text { (B) Group 3B: } \\
\text { Sucrose Test Trial } 1 \\
\text { (generalization) }\end{array}$} & \multicolumn{2}{|c|}{$\begin{array}{c}\text { (C) Group 3A: } \\
\text { Sucrose Test Trial } 1 \\
\text { (control) }\end{array}$} & \multicolumn{2}{|c|}{ A vs. B } & \multicolumn{2}{|c|}{ B vs. C } \\
\hline & $M$ & $S E$ & $M$ & $S E$ & $M$ & $S E$ & $t(3)$ & $p$ & $t(6)$ & $p$ \\
\hline Intake $(\mathrm{ml})$ & 1.00 & 0.30 & 17.90 & 1.71 & 25.43 & 3.21 & -10.42 & .00 & -2.07 & .08 \\
\hline Lick count & 330.00 & 71.26 & $3,843.25$ & 275.31 & $4,105.75$ & 358.77 & -12.94 & .00 & -0.58 & .58 \\
\hline Lick volume $(\mu \mathrm{l})$ & 2.79 & 0.37 & 4.64 & 0.16 & 6.15 & 0.35 & -7.52 & .01 & -3.96 & .01 \\
\hline Meal duration (min) & 12.18 & 0.79 & 13.84 & 0.59 & 14.67 & 0.30 & -2.07 & .13 & -1.26 & .26 \\
\hline Ingestion rate (licks/s) & 0.46 & 0.11 & 4.65 & 0.34 & 4.65 & 0.35 & -12.61 & .00 & -0.02 & .99 \\
\hline Initial lick rate & 42.50 & 14.62 & 401.25 & 6.09 & 355.00 & 13.80 & -19.22 & .00 & 3.07 & .02 \\
\hline Burst count & 43.75 & 9.03 & 26.00 & 4.88 & 20.00 & 3.76 & 1.79 & .17 & 0.97 & .37 \\
\hline Mean burst size (licks) & 7.61 & 0.99 & 162.51 & 27.15 & 219.46 & 25.74 & -5.55 & .01 & -1.52 & .18 \\
\hline Mean burst duration (s) & 1.73 & 0.21 & 23.78 & 3.79 & 32.35 & 3.45 & -5.53 & .01 & -1.67 & .15 \\
\hline Latency (s) & 88.72 & 34.21 & 0.67 & 0.19 & 1.13 & 0.78 & 2.58 & .08 & -0.58 & .58 \\
\hline Pause time $(\%)$ & 89.62 & 2.32 & 31.79 & 4.32 & 31.04 & 5.53 & 12.77 & .00 & 0.11 & .92 \\
\hline Mean pause duration (s) & 17.80 & 3.76 & 10.95 & 1.18 & 17.73 & 5.84 & 2.15 & .12 & -1.13 & .30 \\
\hline Pause ratio & 0.003 & 0.00 & 0.005 & 0.00 & 0.005 & 0.00 & -7.25 & .01 & 0.19 & .86 \\
\hline \multicolumn{11}{|l|}{ ILI range groups } \\
\hline $0-999 \mathrm{~ms}$ & 294.51 & 23.54 & 148.42 & 1.96 & 148.85 & 3.17 & 6.03 & .01 & -0.12 & .91 \\
\hline $0-249 \mathrm{~ms}$ & 137.97 & 3.38 & 141.73 & 1.69 & 146.75 & 3.16 & -1.01 & .39 & -1.40 & .21 \\
\hline $250-499 \mathrm{~ms}$ & 355.97 & 5.46 & 358.51 & 14.42 & 341.78 & 4.38 & -0.26 & .81 & 1.11 & .31 \\
\hline $500-999 \mathrm{~ms}$ & 736.31 & 8.56 & 734.16 & 34.57 & 707.21 & 16.10 & 0.08 & .94 & 0.71 & .56 \\
\hline \multicolumn{11}{|c|}{ Range proportions (\% ILIs in burst) } \\
\hline $0-249 \mathrm{~ms}$ & 60.88 & 7.69 & 98.22 & 0.82 & 99.47 & 0.08 & -4.86 & .02 & -1.50 & .18 \\
\hline $250-499 \mathrm{~ms}$ & 20.13 & 5.96 & 1.01 & 0.38 & 0.23 & 0.08 & 3.25 & .05 & 2.02 & .09 \\
\hline $500-999 \mathrm{~ms}$ & 18.99 & 1.93 & 0.77 & 0.46 & 0.29 & 0.03 & 8.57 & .01 & 1.04 & .34 \\
\hline
\end{tabular}

Note. Bold font indicates that $p$ met the criterion for statistical significance, which was set at $p \leq .05 . \mathrm{LiCl}=$ lithium chloride; CTA $=$ conditioned taste aversion; ILI = interlick interval.

exposure on subsequent T2 tastant responses, we used one-way ANOVA with post hoc comparisons to compare T2 responses across groups. For analysis of lick rates by minute, we used two-way mixed factors (Minute $\times$ Group) ANOVA with post hoc comparisons.

\section{Results and Discussion}

Four rats, 1 in each $\mathrm{LiCl}$ test group, failed to sample the tastant offered in the second half of the test session (T2). Data for these rats were removed from analysis, although the failure of these rats to further sample is discussed.

\section{Intake}

Results indicate that the rapid reduction of $\mathrm{LiCl}$ intake is due in part to avoidance based on a taste association rather than an unconditioned effect of $\mathrm{LiCl}$ per se. $\mathrm{LiCl}$ intake did not differ in the first half of the test session (T1) for the four groups exposed to $\mathrm{LiCl}$ in $\mathrm{T} 1, F(3,20)=2.10, p=.13$ (see Figure 8 ). In the second half of the test session (T2), the rats receiving either $\mathrm{LiCl}$ or $\mathrm{NaCl}$ after $\mathrm{LiCl}$ exhibited significantly less intake compared with their T1 LiCl intake: $\mathrm{LiCl}, F(1,6)=148.71, p<.001 ; \mathrm{NaCl}, F(1,6)=$ $38.45, p<.001$. For rats that received either sucrose or water after $\mathrm{LiCl}$ exposure, intake was not significantly less than it was for $\mathrm{LiCl}$ in T1-sucrose, $F(1,2)=9.17, p=.09$; water, $F(1,6)=$ $2.25, p=.18$ - despite the fact that rats were undoubtedly less dehydrated and were also likely experiencing malaise. However, a direct comparison of $\mathrm{T} 2$ water intakes after $\mathrm{T} 1 \mathrm{LiCl}$ (Group $\mathrm{LiCl}-$ water) and after $\mathrm{T} 1 \mathrm{NaCl}$ exposure (Group $\mathrm{NaCl}$-water) indicates that water intake was significantly lower in the group exposed to $\mathrm{LiCl}, F(1,9)=10.37, p<.01$, although it was also significantly greater $(238 \%)$ than $\mathrm{T} 2 \mathrm{NaCl}$ intake after $\mathrm{LiCl}$ exposure, $F(1,12)=6.93, p<.02$. The pattern of generalization results observed in Experiment 1 was replicated in that a comparison of $\mathrm{T} 2 \mathrm{NaCl}$ and $\mathrm{T} 2 \mathrm{LiCl}$ intakes after $\mathrm{LiCl}$ was not significantly different, $F(1,12)=0.38, p=.55$, and $\mathrm{NaCl}$ intake was significantly lower compared with $\mathrm{T} 2 \mathrm{NaCl}$ in the control group (see Table 8 and Figure 8). Thus, T2 behavior was affected by acute malaise, but it is important to note that there is also evidence that rats can express associative taste aversion learning within 8 min of exposure.

\section{Time Course of Ingestion}

Ingestion rates for $\mathrm{LiCl}$ in $\mathrm{T} 1$ replicated those observed in Experiment 1 . Rats initially drank $\mathrm{LiCl}$ avidly at a rate that did not vary across the four groups exposed to it, $F(3,20)=0.08, p=.97$ (range $=342-362$ licks $/ \mathrm{min}$ ), and was not different from the initial lick rate for $\mathrm{T} 1 \mathrm{NaCl}, F(1,27)=1.03, p=.32$. As the meal progressed, rats ingesting $\mathrm{LiCl}$ exhibited a rapid decline in lick rate, and ingestion almost ceased by the 8 th min (see Figure 9). The shape of the $\mathrm{LiCl}$ ingestion rate curves did not vary substantially across these four groups, as indicated by the lack of a significant main group effect, $F(3,20)=1.49, p=.25$, and the fact that there was no significant Group $\times$ Minute interaction, $F(21,140)=0.72, p=.81$. By contrast, rats in the $\mathrm{NaCl}-\mathrm{NaCl}$ group ingested $\mathrm{NaCl}$ at a sustained and robust pace throughout the entire 8-min T1 test (see Figure 9B), and this curve departed 


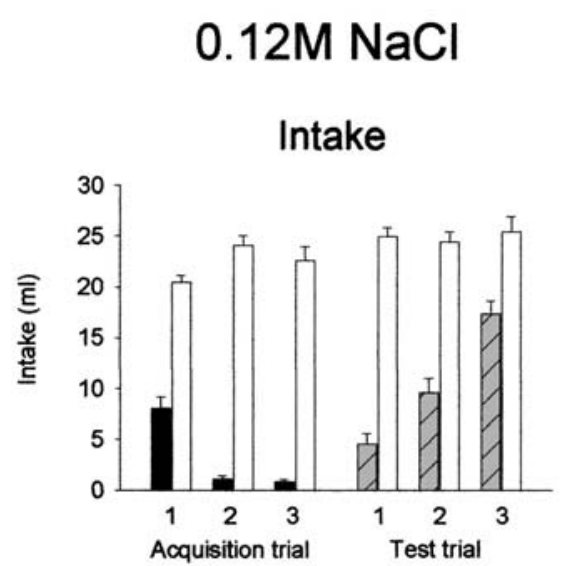

Initial rate

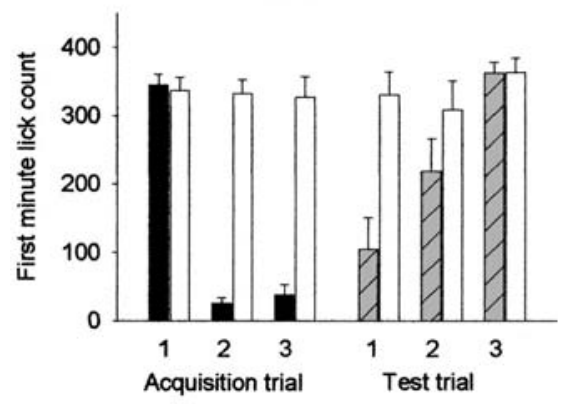

Lick volume
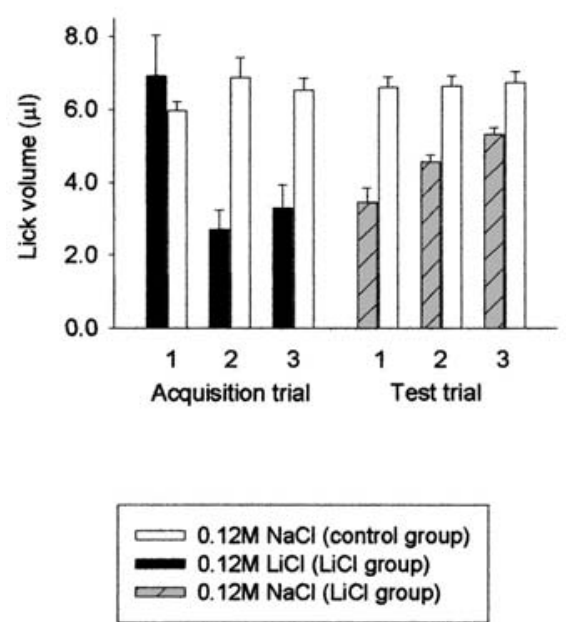

$0.24 \mathrm{M} \mathrm{NaCl}$

Intake

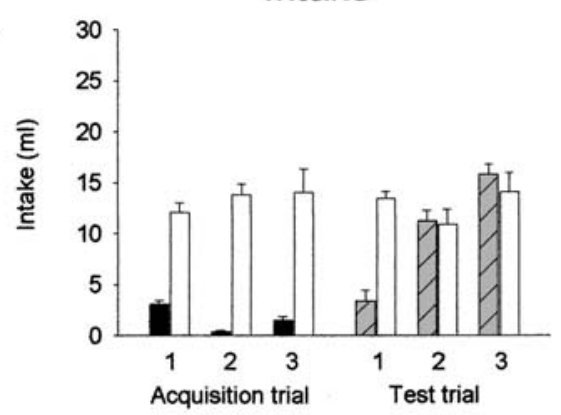

Initial rate

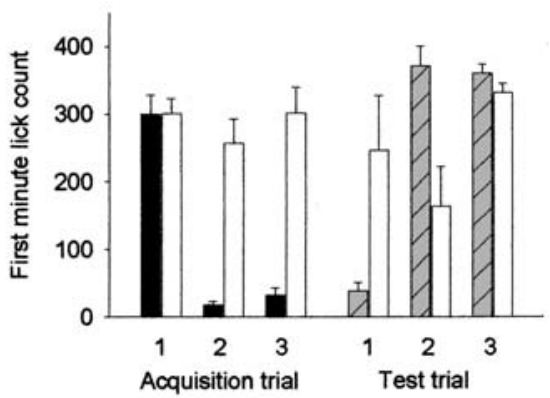

Lick volume
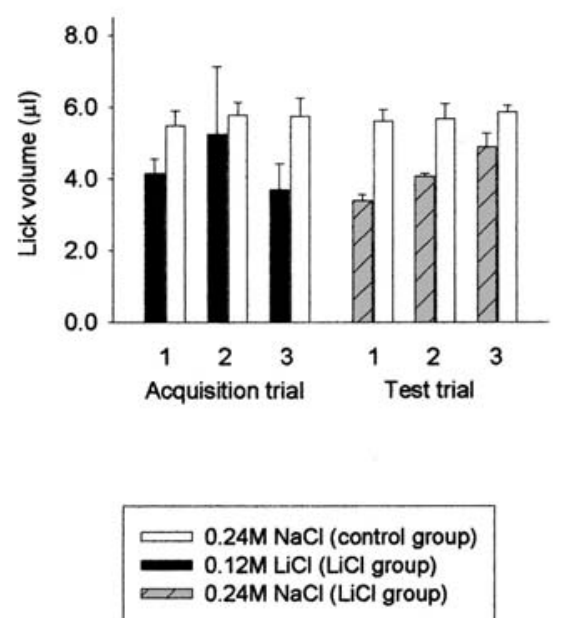

Figure 4. Mean (plus standard error) intake (milliliters), initial lick rate (licks per minute), and lick volume (microliters) across acquisition and test trials for four experimental groups in Experiment 1. Left panels: Data for Groups 1A and 1B. Control rats (Group 1A) drank $0.12 \mathrm{M}$ sodium chloride $(\mathrm{NaCl})$ on all test trials. Group 1B drank $0.12 \mathrm{M}$ lithium chloride $(\mathrm{LiCl})$ on three acquisition trials and $0.12 \mathrm{M} \mathrm{NaCl}$ over three subsequent extinction trials. Right panels: The same measures are plotted for Groups $2 \mathrm{~A}$ and $2 \mathrm{~B}$, for which $0.24 \mathrm{M} \mathrm{NaCl}$ was substituted for $0.12 \mathrm{M} \mathrm{NaCl}$. Thus, Group $2 \mathrm{~B}$ received $0.12 \mathrm{M} \mathrm{LiCl}$ for three acquisition trials, followed by $0.24 \mathrm{M} \mathrm{NaCl}$ across three test trials, and Group 2A received $0.24 \mathrm{M} \mathrm{NaCl}$ across both acquisition and test trials. 

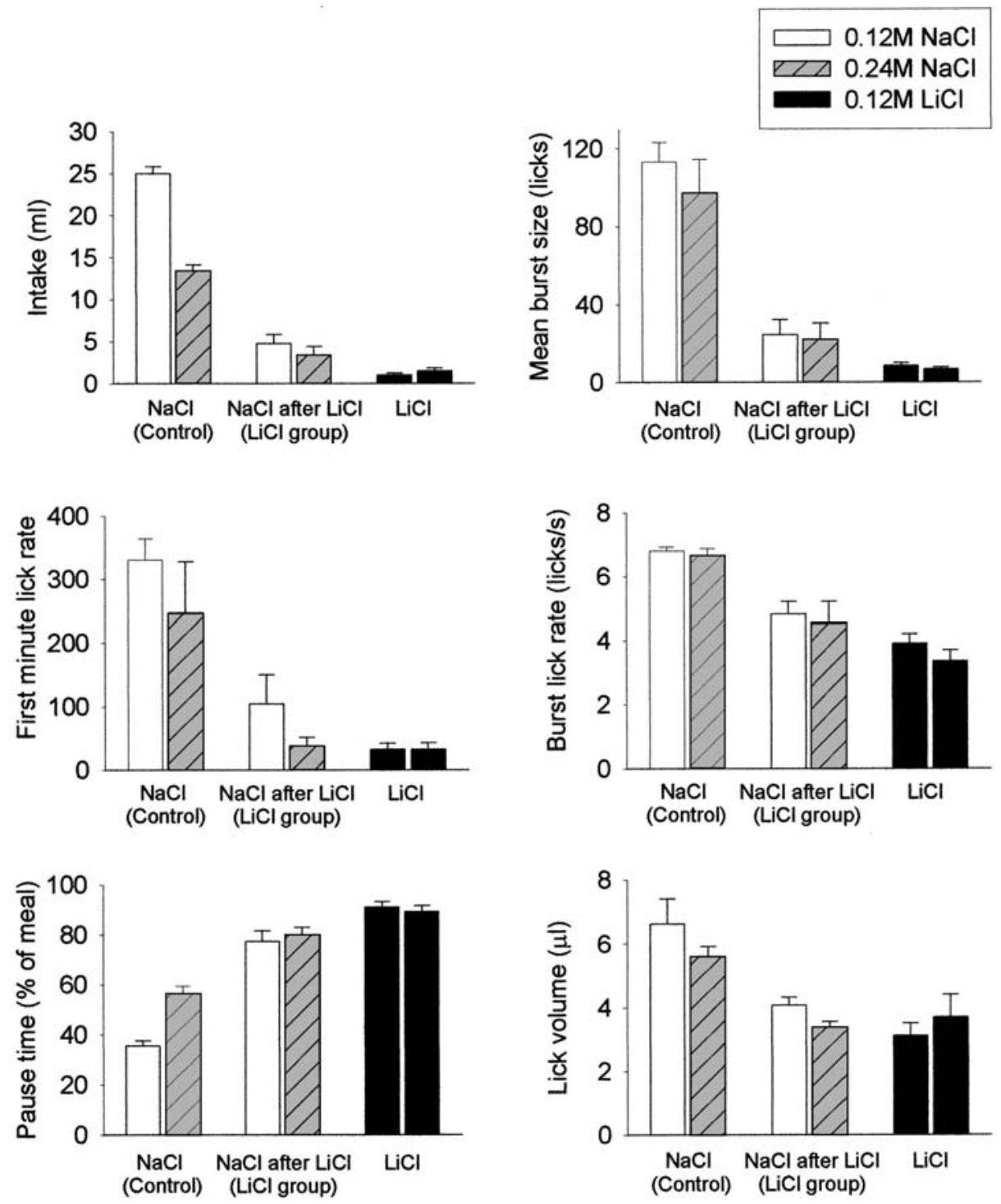

Figure 5. Mean (plus standard error) of six dependent variables for four experimental groups in Experiment 1 depict generalization of lithium chloride $(\mathrm{LiCl})$ conditioned taste aversion to sodium chloride $(\mathrm{NaCl})$. Measures include intake (milliliters), mean burst size (licks per burst), initial lick rate (licks per minute), within-burst lick rate (licks per second), proportion of pause time in the meal (percentage), and lick volume (microliters). The first pair of bars depicts measures on Test Trial 1 for Control Groups $1 \mathrm{~A}(0.12 \mathrm{M} \mathrm{NaCl})$ and $2 \mathrm{~A}(0.24 \mathrm{M} \mathrm{NaCl})$. The middle pair of bars indicates licking measures for matched $\mathrm{NaCl}$ concentrations in Groups $1 \mathrm{~B}(0.12 \mathrm{M} \mathrm{NaCl})$ and $2 \mathrm{~B}(0.24 \mathrm{M} \mathrm{NaCl})$ on the first generalization test after three $\mathrm{LiCl}$ exposures. The final pair indicates values for licking $0.12 \mathrm{M} \mathrm{LiCl}$ on the third acquisition trial in Groups 1B and 2B.

significantly from the $\mathrm{LiCl}$ ingestion rate curve (Group $\mathrm{LiCl}-$ $\mathrm{NaCl}$ ) by the 7th min: interaction, $F(7,77)=5.90, p<.001$.

In $\mathrm{T} 2$, the ingestion rate curves, which had been roughly uniform when the rats were ingesting $\mathrm{LiCl}$ in $\mathrm{T} 1$, now diverged significantly depending on what tastant was offered. It should be noted that 1 rat in each treatment group failed to sample the T2 tastant. Of rats that did sample the T2 tastant, there was no systematic or statistical difference in latency either across groups, $F(4,27)=2.35, p=.09$, or relative to water habituation trials $($ mean latency $=23.9 \mathrm{~s}), F(1,20)=3.55, p>.07$.
As shown in Figure 9A, rats that sampled $\mathrm{NaCl}$ or $\mathrm{LiCl}$ in $\mathrm{T} 2$ exhibited an approximate halving of ingestion rate in the 1st min relative to the 1 st min of licking for either $\mathrm{T} 1 \mathrm{LiCl}$ (52\% suppression), $F(1,6)=6.12, p<.05$, or $\mathrm{T} 1 \mathrm{NaCl}$ (49\% suppression), $F(1$, $6)=6.52, p<.03$. The $\mathrm{T} 2 \mathrm{NaCl}$ initial rate after $\mathrm{T} 1 \mathrm{LiCl}$ exposure was also $39 \%$ lower relative to $\mathrm{T} 2 \mathrm{NaCl}$ control $(\mathrm{NaCl}-\mathrm{NaCl}$ group) values, $F(1,11)=4.85, p=.05$ (see Figure 9B). In the remaining minutes of the test session, ingestion rate for both $\mathrm{LiCl}$ and $\mathrm{NaCl}$ rapidly declined, in almost parallel fashion, to negligible values within 6 min for rats exposed to $\mathrm{T} 1 \mathrm{LiCl}$ (see Figure 9A). 


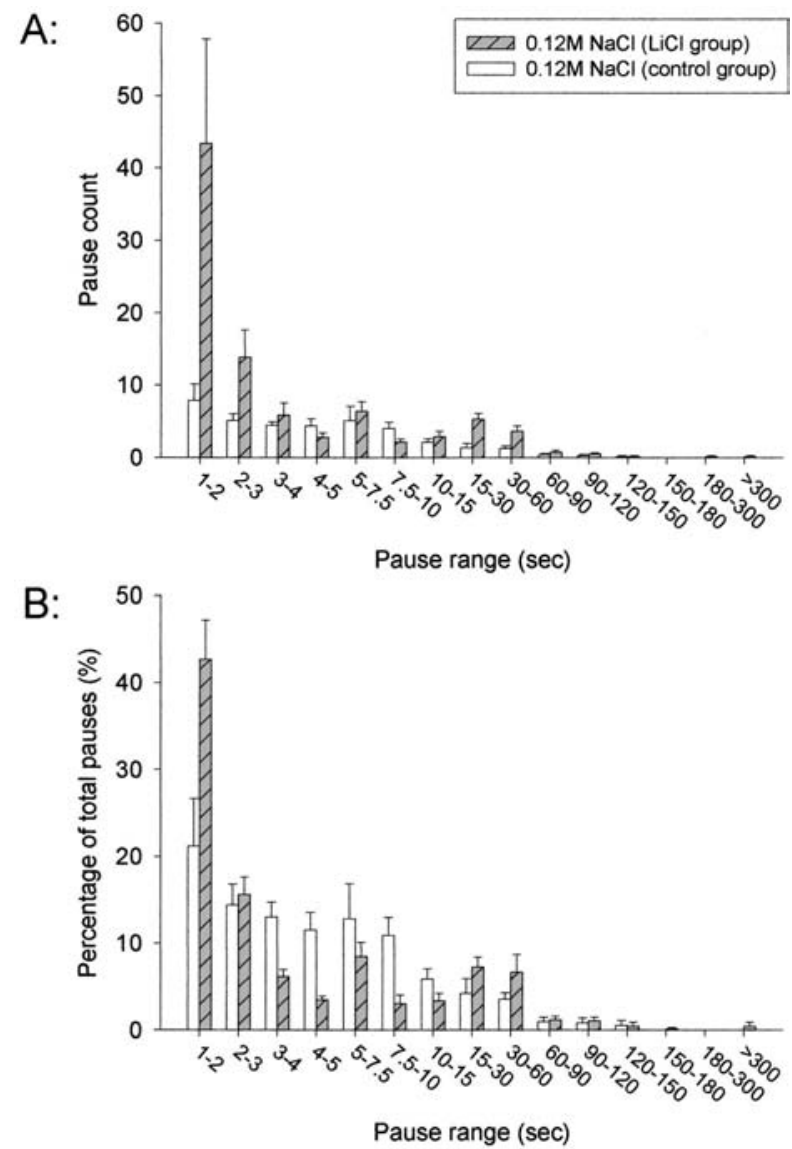

Figure 6. A: Frequency distribution of pauses for $0.12 \mathrm{M}$ sodium chloride $(\mathrm{NaCl})$ on Test Trial 1 by rats in the control Group $1 \mathrm{~A}$ and the lithium chloride ( $\mathrm{LiCl}$ )-exposed Group 1B. Mean (plus standard error) pause counts in each range are plotted. Range labels have been simplified for clarity of presentation. Range categories include pauses equal to or greater than the lower value through to pauses up to $1 \mathrm{~ms}$ less than the upper value indicated. For example, the 15-30 s category includes pauses of 15,000 ms through 29,999 ms. B: Same data as in Panel A, except that pause counts in each range are plotted as a proportion of all pauses in the meal.

At no time point were the ingestion rates significantly different for either $\mathrm{T} 2 \mathrm{NaCl}$ or $\mathrm{T} 2 \mathrm{LiCl}$ after $\mathrm{T} 1 \mathrm{LiCl}$, as there was no significant between-groups difference in lick rate, $F(1,12)=0.88, p=$ .37 , and no significant Group $\times$ Minute interaction, $F(4,48)=$ $0.29, p=.88$. There was a significant main effect of minute, $F(4$, $48)=15.19, p=.002$, indicating a general decline in lick rate. A comparison of $\mathrm{T} 2 \mathrm{NaCl}$ lick rates after either $\mathrm{T} 1 \mathrm{LiCl}$ or $\mathrm{T} 1 \mathrm{NaCl}$ also revealed that licking for $\mathrm{NaCl}$ after $\mathrm{LiCl}$ was markedly suppressed relative to control rats' licking of $\mathrm{NaCl}$ after $\mathrm{T} 1 \mathrm{NaCl}$ (see Figure 9B), as there was a significant main effect of group, $F(1$, $11)=53.03, p<.001$. There was no significant interaction, $F(7$, $77)=0.75, p=.64$, although there was a main effect of minute, $F(7,77)=6.11, p<.001$, indicating a declining lick rate for both groups (see Figure 9B).

In contrast, Figure 9C shows that rats offered water or sucrose after $\mathrm{LiCl}$ exhibited a rapid reinvigoration of ingestion rate. The 1st-min lick rate for sucrose more than doubled that for $\mathrm{T} 2 \mathrm{LiCl}$, $F(1,9)=7.46, p=.03$, or $\mathrm{NaCl}, F(1,9)=5.51, p=.05$. Water licking was initially unaffected by prior $\mathrm{T} 1 \mathrm{LiCl}$ ingestion: The 1st-min lick rate for $\mathrm{T} 2$ water licking in the $\mathrm{LiCl}$-water group was almost identical to that for the $\mathrm{NaCl}$-water control group (see Table 9). The initial lick rate for T2 water more than doubled that for $\mathrm{T} 2 \mathrm{LiCl}, F(1,13)=6.03, p=.03$, and was $72 \%$ greater than the $\mathrm{T} 2 \mathrm{NaCl}$ initial lick rate, $F(1,13)=3.73, p=.07$.

Throughout the remainder of $\mathrm{T} 2$, both sucrose and water lick rates gradually declined: minute, $F(7,56)=4.82, p<.001$. The rate of licking for water overall was slower than for sucrose, as shown by a significant main effect of group, $F(1,8)=42.28, p<$ .001 , although the interaction term was not significant, $F(14$, $56)=2.22, p=.08$. The lick rate for $\mathrm{T} 2$ water after $\mathrm{T} 1 \mathrm{LiCl}$ was also significantly slower than for T2 water after T1 $\mathrm{NaCl}, F(1$, $9)=91.28, p<.001$, but it was also significantly greater than for $\mathrm{T} 2 \mathrm{NaCl}$ after $\mathrm{T} 1 \mathrm{LiCl}, F(1,12)=26.76, p<.001$. Thus, water ingestion after $\mathrm{LiCl}$ was partially suppressed, but significantly less so than licking for $\mathrm{NaCl}$ after $\mathrm{T} 1 \mathrm{LiCl}$.

\section{Microstructure}

In Experiment 1, $\mathrm{LiCl}$ exposure resulted in reduced lick volume and burst size and duration, increased burst count, and increases in ILI and pause measures, such that the rate of ingestion within bursts (and for the overall meal) was slower. In this section we evaluate whether such changes occur within a single test session by comparing $\mathrm{T} 1$ and $\mathrm{T} 2$ microstructural measures.

Burst structure. The number of bursts of $\mathrm{LiCl}$ licking in $\mathrm{T} 1 \mathrm{did}$ not differ across the four LiCl-exposed groups (range $=13.33 \pm$ 2.60 to $18.57 \pm 2.06), F(1,6)=0.54, p=.66$, and, in replication of Experiment 1, roughly doubled the number of bursts of $\mathrm{T} 1 \mathrm{NaCl}$ licking by the $\mathrm{NaCl}-\mathrm{NaCl}$ group, $F(1,27)=5.08, p<.03$. Further, the average burst size for $\mathrm{T} 1 \mathrm{LiCl}$ was roughly one third of that for $\mathrm{T} 1 \mathrm{NaCl}, F(1,6)=29.53, p<.001$. When LiClexposed rats were offered $\mathrm{LiCl}$ or $\mathrm{NaCl}$ in $\mathrm{T} 2$, both the number of bursts-LiCl-LiCl, $F(1,6)=51.98, p<.001 ; \mathrm{LiCl}-\mathrm{NaCl}, F(1$, $6)=15.29, p<.01$-and the mean burst sizes- $\mathrm{LiCl}-\mathrm{LiCl}$ group, $F(1,6)=21.92, p=.003 ; \mathrm{LiCl}-\mathrm{NaCl}$ group, $F(1,7)=7.20, p<$ .04 -were dramatically reduced relative to $\mathrm{T} 1$. Compared with controls ( $\mathrm{NaCl}-\mathrm{NaCl}$ group), burst size for $\mathrm{T} 2 \mathrm{NaCl}$ ingestion was reduced more than threefold as a result of $\mathrm{LiCl}$ preexposure (see Table 8).

In groups $\mathrm{LiCl}$-sucrose and $\mathrm{LiCl}$-water, for which $\mathrm{T} 2$ intake was less affected by $\mathrm{T} 1 \mathrm{LiCl}$ drinking, the number of bursts and average burst sizes were not significantly different from those for T1 LiCl: LiCl-sucrose, $F(1,2)=2.17, p=.28 ; \mathrm{LiCl}$-water, $F(1$, $6)=1.14, p=.33$. However, the mean burst size for water intake in $\mathrm{T} 2$ was more than halved relative to the $\mathrm{NaCl}$-water control group (see Table 9). The number of bursts was not significantly different in this T2 water-water group comparison (see Table 9).

ILIs. In Experiment 1 we observed that CTA slowed licking within bursts (see Figure 2). This effect was carried by a proportional increase in longer ILIs (250-999 ms) within bursts. The results of Experiment 2 convey a consistent trend toward replication of this effect, although effects were less robust.

Overall, licking within bursts was slowed from an average of $6.29 \pm 0.19$ licks/s for $\mathrm{T} 1 \mathrm{LiCl}$ to $4.76 \pm 0.56$ licks/s for $\mathrm{T} 2 \mathrm{LiCl}$, $F(1,6)=3.37, p=.11$, and $5.05 \pm 0.55$ licks/s for $\mathrm{T} 2 \mathrm{NaCl}$ in Group LiCl-NaCl, $F(1,6)=2.60, p=.16$ (see also Table 8). By comparison, licking within bursts was slightly faster for sucrose 
Table 6

$\mathrm{NaCl} \mathrm{CTA}$ Extinction Trial 3 Compared With $\mathrm{NaCl}$ Controls

\begin{tabular}{|c|c|c|c|c|c|c|}
\hline \multirow[b]{2}{*}{ Measure } & \multicolumn{2}{|c|}{$\begin{array}{l}\text { Group 1A: } \mathrm{NaCl} \\
\text { Test Trial } 3 \\
\text { (control group) }\end{array}$} & \multicolumn{2}{|c|}{$\begin{array}{l}\text { Group 1B: } \mathrm{NaCl} \\
\text { Test Trial } 3 \\
\text { (CTA group) }\end{array}$} & \multirow[b]{2}{*}{$t(7)$} & \multirow[b]{2}{*}{$p$} \\
\hline & $M$ & $S E$ & $M$ & $S E$ & & \\
\hline Intake (ml) & 25.42 & 1.47 & 17.63 & 1.21 & -4.08 & .00 \\
\hline Lick count & $3,786.88$ & 191.27 & $3,263.75$ & 203.47 & -1.87 & .08 \\
\hline Lick volume $(\mu \mathrm{l})$ & 6.73 & 0.29 & 5.40 & 0.19 & -3.70 & .00 \\
\hline Meal duration (min) & 13.93 & 0.56 & 13.85 & 0.37 & 0.12 & .90 \\
\hline Ingestion rate (licks/s) & 4.56 & 0.23 & 3.96 & 0.30 & -1.59 & .13 \\
\hline Initial lick rate & 363.13 & 21.68 & 362.75 & 15.61 & 0.01 & .99 \\
\hline Burst count & 27.62 & 4.94 & 27.38 & 6.11 & 0.03 & .98 \\
\hline Mean burst size (licks) & 169.88 & 27.13 & 170.29 & 36.08 & 0.01 & .99 \\
\hline Mean burst duration (s) & 24.78 & 3.86 & 25.08 & 5.16 & 0.05 & .96 \\
\hline Latency (s) & 3.03 & 1.71 & 1.28 & 0.84 & -0.92 & .37 \\
\hline Pause time $(\%)$ & 33.09 & 3.50 & 41.40 & 4.07 & 1.55 & .14 \\
\hline Mean pause duration (s) & 16.62 & 4.93 & 17.76 & 3.28 & 0.19 & .85 \\
\hline Pause ratio & 0.01 & 0.00 & 0.01 & 0.00 & 0.73 & .48 \\
\hline \multicolumn{7}{|l|}{ ILI range groups } \\
\hline 0-999 ms & 147.78 & 1.96 & 150.13 & 3.20 & 0.63 & .54 \\
\hline $0-249 \mathrm{~ms}$ & 142.82 & 2.46 & 141.03 & 2.54 & 0.51 & .62 \\
\hline $250-499 \mathrm{~ms}$ & 343.19 & 8.27 & 346.08 & 6.23 & 0.28 & .79 \\
\hline 500-999 ms & 674.85 & 29.06 & 702.17 & 11.60 & 0.84 & .41 \\
\hline \multicolumn{7}{|c|}{ Range proportions (\% ILIs in burst) } \\
\hline $0-249 \mathrm{~ms}$ & 98.39 & 0.51 & 97.24 & 0.56 & -1.52 & .15 \\
\hline $250-499 \mathrm{~ms}$ & 1.07 & 0.37 & 1.81 & 0.28 & 1.57 & .14 \\
\hline $500-999 \mathrm{~ms}$ & 0.53 & 0.15 & 0.95 & 0.29 & 1.25 & .23 \\
\hline
\end{tabular}

Note. Bold font indicates that $p$ met the criterion for statistical significance, which was set at $p \leq .05$. $\mathrm{NaCl}=$ sodium chloride; CTA = conditioned taste aversion; ILI = interlick interval.

after $\mathrm{T} 1 \mathrm{LiCl}(6.53 \pm 0.32 \mathrm{lick} / \mathrm{s}), F(1,6)=17.69, p=.05$, and T2 lick rates for water were not different from the rates for the $\mathrm{NaCl}-$ water group (see Table 9). The mean durations of ILIs in the 0-249 ms range were not significantly different in the T2 test between the $\mathrm{LiCl}-\mathrm{NaCl}$ and $\mathrm{LiCl}-\mathrm{LiCl}$ groups, $F(1,13)=0.02$, $p=.90$; between the $\mathrm{LiCl}-$ water and $\mathrm{NaCl}-$ water groups (see Table 9); or between the $\mathrm{LiCl}-\mathrm{NaCl}$ and $\mathrm{NaCl}-\mathrm{NaCl}$ groups (see Table 8). The average of ILIs in the 250-499 ms range was somewhat (about 10\%) shortened for $\mathrm{T} 2$ water after $\mathrm{T} 1 \mathrm{LiCl}$ (see Table 9), but no other effects were observed ( $p$ s $>.10$; see Table
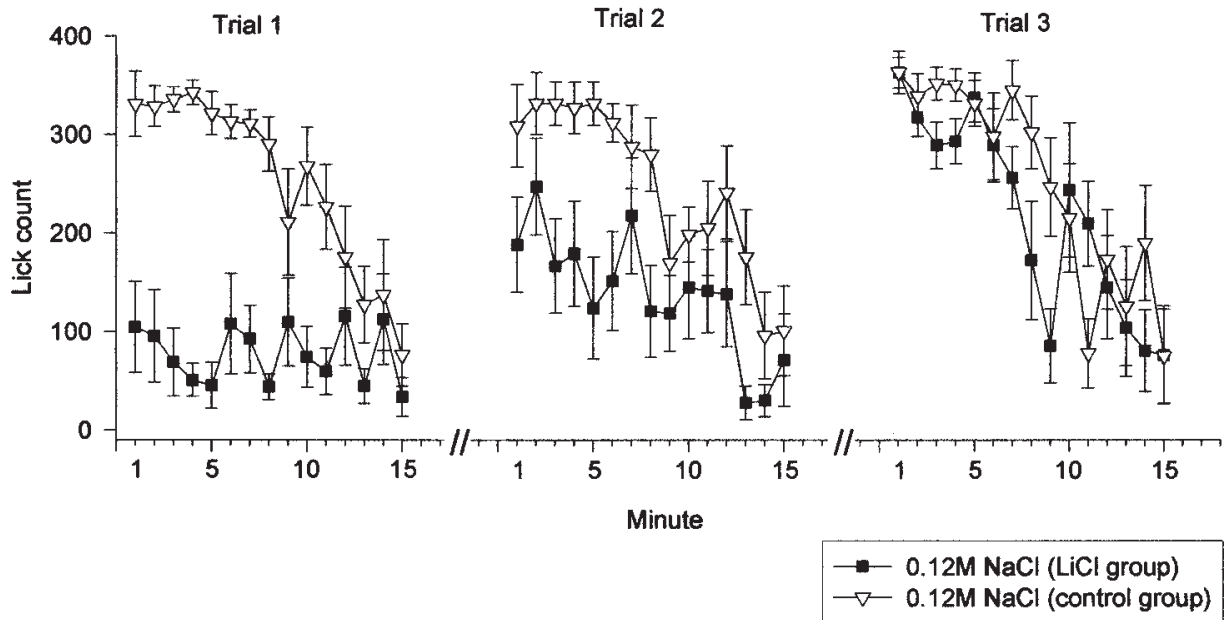

Figure 7. Mean (plus or minus standard error) lick rates (licks per minute) for rats drinking $0.12 \mathrm{M}$ sodium chloride $(\mathrm{NaCl})$ across three extinction trials. Lick rates for rats in the control group (Group 1A; $n=8$ ) were consistent across all three trials. For rats in the lithium chloride $(\mathrm{LiCl})$ group (Group $1 \mathrm{~B} ; n=8$ ), prior exposure to $\mathrm{LiCl}$ markedly suppressed $\mathrm{NaCl}$ drinking throughout the first test trial. Gradual extinction was apparent through successive increases in the rates of licking over the first half of the meal on Trials 2 and 3. 
Table 7

Experiment 2: Summary of Conditions

\begin{tabular}{lll}
\hline \multicolumn{1}{c}{ Group } & $\begin{array}{c}\text { T1 tastant } \\
\text { (first } 8 \text { min) }\end{array}$ & $\begin{array}{c}\text { T2 tastant } \\
\text { (second } 8 \text { min) }\end{array}$ \\
\hline $\mathrm{LiCl}-\mathrm{LiCl}(n=8)$ & $0.12 \mathrm{M} \mathrm{LiCl}$ & $0.12 \mathrm{M} \mathrm{LiCl}$ \\
$\mathrm{LiCl}-\mathrm{NaCl}(n=8)$ & $0.12 \mathrm{M} \mathrm{LiCl}$ & $0.12 \mathrm{M} \mathrm{NaCl}$ \\
$\mathrm{NaCl}-\mathrm{NaCl}(n=6)$ & $0.12 \mathrm{M} \mathrm{NaCl}$ & $0.12 \mathrm{M} \mathrm{NaCl}$ \\
$\mathrm{LiCl}-$ sucrose $(n=4)$ & $0.12 \mathrm{M} \mathrm{LiCl}$ & $0.12 \mathrm{M} \mathrm{sucrose}$ \\
$\mathrm{LiCl}-$ water $(n=8)$ & $0.12 \mathrm{M} \mathrm{LiCl}$ & Water \\
$\mathrm{NaCl}-$ water $(n=4)$ & $0.12 \mathrm{M} \mathrm{NaCl}$ & Water \\
\hline
\end{tabular}

Note. $\mathrm{T}=$ trial; $\mathrm{LiCl}=$ lithium chloride; $\mathrm{NaCl}=$ sodium chloride.

$8)$. No significant differences were observed for ILIs in the 500999 ms range ( $p$ s $>.17$; see Tables 8 and 9).

The proportion of within-burst ILIs in the $0-249 \mathrm{~ms}$ range was reduced from a mean of $97.25 \% \pm 0.71 \%$ for $\mathrm{T} 1 \mathrm{LiCl}$ to $81.35 \%$ $\pm 7.47 \%$ for $\mathrm{T} 2 \mathrm{LiCl}, F(1,6)=5.54, p=.06$, and to $83.95 \% \pm$ $7.04 \%$ for $\mathrm{T} 2 \mathrm{NaCl}$ in the $\mathrm{LiCl}-\mathrm{NaCl}$ group, $F(1,6)=3.97, p=$ .09 (see Table 8 ). The proportions of these ILIs were not appreciably reduced for $\mathrm{T} 2$ sucrose $(96.72 \% \pm 0.19 \%)$ or $\mathrm{T} 2$ water $(94.72 \% \pm 1.50 \%)$ after $\mathrm{T} 1 \mathrm{LiCl}$. The proportional loss of T2 ILIs $0-249 \mathrm{~ms}$ for the $\mathrm{LiCl}-\mathrm{NaCl}$ and $\mathrm{LiCl}-\mathrm{LiCl}$ groups was offset by increases in T2 ILIs $250-499 \mathrm{~ms}$ (LiCl-LiCl: $10.52 \% \pm 5.32 \%$; LiCl-NaCl: $9.92 \% \pm 4.30 \%)$ and T2 ILIs 500-999 ms (LiClLiCl: $8.13 \% \pm 3.47 \%$; LiCl-NaCl: $6.13 \% \pm 2.82 \%$ ).

Lick volume. Lick volume fluctuated little between T1 and T2 tests (no more than 12\%), and no comparisons were significantly different $(p s>.13)$, except for water intake after $\mathrm{T} 1 \mathrm{LiCl}$, which was reduced $12 \%$ relative to $\mathrm{T} 1 \mathrm{LiCl}, F(3,23)=6.95, p<.04$. Experiment 3 was developed to explore the nature of this discrepancy with Experiment 1.

\section{Experiment 3}

\section{Method}

In Experiment 1, lick volume was reduced by more than $40 \%$ on $\mathrm{LiCl}$ Trials 2 and 3 and was more resistant to extinction than most other measures (see Figure 4). In Experiment 2, lick volumes fluctuated little throughout the single test trial. Rats can vary lick topography rapidly on the basis of taste. For example, rats exposed to $\mathrm{QHCl}$ in a single trial expressed a halved lick volume relative to water licking (Spector \& St. John, 1998). Therefore, the delayed expression of lick volume changes may indicate a delayed associative effect of CTA conditioning. One caveat to this interpretation is that for Experiment 2 we used a different apparatus, in which the spout was recessed about $5 \mathrm{~mm}$ more than in the lickometer used in Experiment 1. It is plausible that rats in Experiment 2 had less freedom to control lick volume because the longer tongue protrusion requirements diminished their ability to extrude larger drops from the spout (e.g., Weijnen, 1998). To test this hypothesis, we used the same procedures as those for the $\mathrm{LiCl}-\mathrm{LiCl}$ group in Experiment 2 to expose 4 naive rats $(278 \pm 4 \mathrm{~g})$ to $0.12 \mathrm{M} \mathrm{LiCl}$, with the modification that rats were tested for 2 consecutive $\mathrm{LiCl}$ days.

\section{Results and Discussion}

Consistent with Experiment 2, 1 rat failed to sample $\mathrm{LiCl}$ in the $\mathrm{T} 2$ phase of the 1 st $\mathrm{LiCl}$ test day. Also, 2 rats failed to sample $\mathrm{LiCl}$ in the $\mathrm{T} 1$ and/or the $\mathrm{T} 2$ session of the 2 nd $\mathrm{LiCl}$ test day. Although a strong aversion was formed, all rats made at least 88 licks when they did sample $\mathrm{LiCl}$, permitting analysis of lick volume. As there was no obvious difference (data not shown) in the T1 to T2 lick volume measures (consistent with Experiment 2), we collapsed lick volume data for each rat across $\mathrm{T} 1$ and $\mathrm{T} 2$ periods to yield an average lick volume score for each test day.

Results for the two daily $\mathrm{LiCl}$ trials were compared with the water trial preceding the $1 \mathrm{st} \mathrm{LiCl}$ test day via a one-way repeatedmeasures ANOVA with post hoc comparisons. For the water habituation test, mean lick volume was $4.47 \pm 0.10 \mu \mathrm{L}$. Mean lick volume declined little on the $1 \mathrm{st} \mathrm{LiCl}$ test day; it was $3.87 \pm 0.34$ $\mu \mathrm{L}$. However, mean lick volume was more than halved on the 2 nd $\mathrm{LiCl}$ test day, to $2.19 \pm 0.21 \mu \mathrm{L}$. This reduction was significantly different from the water trial, $F(2,4)=2.64, p=.001$ (comparison $p=.02$ ). We conclude that lick volume reduction is a delayed associative outcome of CTA learning.

\section{General Discussion \\ CTA Microstructure}

We used lick microstructure analysis to characterize the formation of a CTA in rats ingesting $\mathrm{LiCl}$. This method approximates toxin exposure under feral conditions and allows for real time analysis of the formation of the aversion. In Experiment 1 rats showed a rapid decline in lick rate for $\mathrm{LiCl}$ on the first trial. By the second and third $\mathrm{LiCl}$ trials, profound shifts in the meal pattern were evident: The initial lick rate was reduced tenfold, bursts were dramatically reduced in size but increased in number, and the rate of ingestion both within and across bursts was slowed markedly. By all measures, it appears that CTA-treated rats were thirsty but also were hesitant to remain at the spout.

The pattern of microstructural changes we observed after CTA formation has not been reported for other treatments that suppress

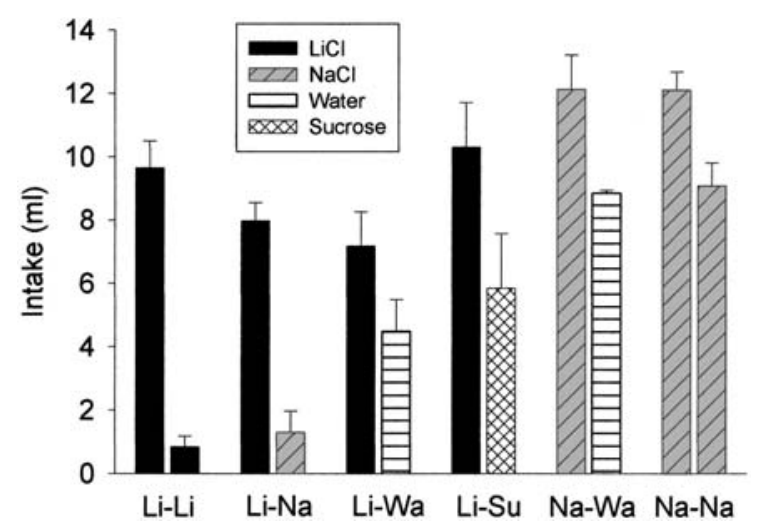

Figure 8. Mean (plus standard error ) intake values for tastants offered in the first $8 \mathrm{~min}$ (first bar in each pair) and second $8 \mathrm{~min}$ (second bar in each pair) of the test session, for all test groups in Experiment 2. Tastants were $0.12 \mathrm{M}$ lithium chloride $(\mathrm{LiCl}), 0.12 \mathrm{M}$ sodium chloride $(\mathrm{NaCl}), 0.12 \mathrm{M}$ sucrose, and distilled water. Labels on the abscissa indicate the experimental test groups (see Table 7). $\mathrm{Li}-\mathrm{Li}=\mathrm{LiCl}$ offered in both parts of the test session; $\mathrm{Li}-\mathrm{Na}=\mathrm{LiCl}$ offered first, then $\mathrm{NaCl}$; $\mathrm{Li}-\mathrm{Wa}=\mathrm{LiCl}$ offered first, then water; $\mathrm{Li}-\mathrm{Su}=\mathrm{LiCl}$ offered first, then sucrose; $\mathrm{Na}-\mathrm{Wa}=\mathrm{NaCl}$ offered first, then water; $\mathrm{Na}-\mathrm{Na}=\mathrm{NaCl}$ offered in both parts of the test session. 
Table 8

$\mathrm{NaCl}$ Responses After $\mathrm{LiCl}$ or $\mathrm{NaCl}$ Ingestion

\begin{tabular}{|c|c|c|c|c|c|c|}
\hline \multirow[b]{2}{*}{ Measure } & \multicolumn{2}{|c|}{$\begin{array}{c}\mathrm{T} 2 \mathrm{NaCl} \text { after } \\
\mathrm{T} 1 \mathrm{NaCl}\end{array}$} & \multicolumn{2}{|c|}{$\begin{array}{l}\mathrm{T} 2 \mathrm{NaCl} \text { after } \\
\mathrm{T} 1 \mathrm{LiCl}\end{array}$} & \multirow[b]{2}{*}{$t(13)$} & \multirow[b]{2}{*}{$p$} \\
\hline & $M$ & $S E$ & $M$ & $S E$ & & \\
\hline Intake $(\mathrm{ml})$ & 9.08 & 0.73 & 1.49 & 0.64 & -7.88 & .00 \\
\hline Lick count & $1,635.63$ & 246.91 & 343.43 & 158.02 & -4.26 & .00 \\
\hline Lick volume $(\mu \mathrm{l})$ & 4.78 & 0.24 & 4.69 & 0.33 & -0.22 & .83 \\
\hline Drinking duration (min) & 7.79 & 0.10 & 3.36 & 0.98 & -4.12 & .00 \\
\hline Ingestion rate (licks/s) & 4.07 & 0.29 & 2.31 & 0.86 & -1.82 & .10 \\
\hline Initial lick rate & 331.67 & 22.60 & 184.85 & 58.25 & -2.20 & .05 \\
\hline Burst count & 16.33 & 2.64 & 8.86 & 2.73 & -1.95 & .08 \\
\hline Mean burst size (licks) & 137.07 & 25.70 & 45.62 & 19.97 & -2.85 & .02 \\
\hline Mean burst duration (s) & 21.64 & 4.00 & 7.40 & 3.11 & -2.85 & .02 \\
\hline Latency (s) & 0.14 & 0.00 & 40.03 & 12.26 & 5.78 & .04 \\
\hline Pause time $(\%)$ & 35.47 & 3.60 & 62.26 & 13.34 & 1.80 & .10 \\
\hline Mean pause duration (s) & 13.62 & 3.80 & 39.31 & 14.70 & 1.57 & .15 \\
\hline Pause ratio & 0.01 & 0.00 & 0.06 & 0.02 & 2.46 & .03 \\
\hline \multicolumn{7}{|l|}{ ILI range groups } \\
\hline $0-999 \mathrm{~ms}$ & 158.59 & 4.86 & 198.71 & 21.82 & 1.66 & .13 \\
\hline $0-249 \mathrm{~ms}$ & 153.93 & 4.65 & 145.05 & 3.35 & -1.58 & .14 \\
\hline 250-499 ms & 346.87 & 3.40 & 350.98 & 7.62 & 0.47 & .65 \\
\hline $500-999 \mathrm{~ms}$ & 680.78 & 24.59 & 607.30 & 106.22 & -0.62 & .55 \\
\hline \multicolumn{7}{|c|}{ Range proportions (\% ILIs in burst) } \\
\hline $0-249 \mathrm{~ms}$ & 98.51 & 0.02 & 83.95 & 0.07 & -1.90 & .08 \\
\hline $250-499 \mathrm{~ms}$ & 0.97 & 0.14 & 9.93 & 4.30 & 1.91 & .08 \\
\hline $500-999 \mathrm{~ms}$ & 0.52 & 0.12 & 6.13 & 2.82 & 1.83 & .10 \\
\hline
\end{tabular}

Note. Bold font indicates that $p$ met the criterion for statistical significance, which was set at $p \leq .05$. $\mathrm{NaCl}=$ sodium chloride; $\mathrm{LiCl}=$ lithium chloride; $\mathrm{T}=$ trial; ILI $=$ interlick interval.

feeding by state or pharmacological manipulation. Caloric gastric preloads reduced the number and size of bursts in the meal and, like hepatic-portal glucose infusions, also suppressed the average ingestion rate (Baird et al., 1999; Eisen et al., 2001). Satiety-related drug treatments, including cholecystokinin, d-fenfluramine, and Melanotan II infusions, were shown to suppress meal duration, number of bursts, ${ }^{1}$ and average ingestion rate (Davis, Smith, \& Kung, 1995; Kaplan, Donahey, Baird, Simansky, \& Grill, 1997; Williams, Grill, Weiss, Baird, \& Kaplan, 2002). We also observed a reduction in mean burst size and average ingestion rate; however, CTA-induced intake reduction was accompanied by reduced lick volume and within-burst lick rate and by a paradoxical increase in the number of bursts. These latter effects were not reported in the studies noted above.

Our results do compare favorably with the prevailing scattered evidence of CTA licking responses in the literature. Kent et al. (2002) evaluated $0.3 \mathrm{M}$ sucrose licking on 3 CTA acquisition trials. Rats progressively reduced intake and burst size but did not increase the number of bursts, as we observed. This discrepancy may relate to CTA strength: Rats in our study ingested a relatively larger dose of $\mathrm{LiCl}(3.50 \mathrm{mEq} / \mathrm{kg}$ vs. $0.75 \mathrm{mEq} / \mathrm{kg})$ and reduced intake to a much greater degree ( $92 \%$ vs. $21 \%$ suppression). Davis and Perez evaluated licking responses to saccharin during and after $\mathrm{LiCl}$ exposure (reported in Davis, 1998). They observed a decline in both intake and initial lick rate during $\mathrm{LiCl}$ training, which gradually reversed over 10 extinction trials. Additional microstructure measures were not reported. Our results are consistent, except that extinction occurred more rapidly, within 3 trials. This was likely due to our water restriction paradigm, in which rats were only allowed access to fluids during the 15-min test sessions.
Finally, Aja and colleagues (Aja, Robinson, Mills, Ladenheim, \& Moran, 2002; Aja, Schwartz, Kuhar, \& Moran, 2001) observed that intracerebroventricular (ICV) infusions of cocaine- and amphetamine-related transcript (CART) suppressed intake but also produced a CTA and tremors. They found a slower rate of licking within bursts and a slowed rate of ingestion overall, as we also observed.

During CTA, rats ingested at an almost $50 \%$ slower rate within bursts because of an increase in the proportion of longer ILIs (250-999 ms) relative to shorter ILIs (less than $250 \mathrm{~ms}$ ). The lack of influence on ILIs less than $250 \mathrm{~ms}$ suggests that $\mathrm{LiCl}$ exposure did not significantly disrupt the rhythmic timing functions of the central pattern generator for licking in the reticular formation (Travers, Dinardo, \& Karimnamazi, 1997) but rather affected processes that engage and disengage bursts of licking.

In contrast to the increased average ILI duration within bursts, we observed no overall effect on average pause duration. Rather, the average size and duration of bursts were markedly reduced, and the pause count was increased, such that the proportion of meal time expressed in pauses significantly increased. Combined with a slower rate of licking within bursts and no change in meal duration, rats ingested at an average lick rate that was $60 \%$ to $90 \%$ slower under CTA conditions.

Although there was no overall effect on mean pause duration, CTA treatment produced an increase in brief pauses (1-2 s) in the meal (see Figure 6). Considering the parallel increase in long ILIs within bursts, we conclude that CTA treatment specifically in-

\footnotetext{
${ }^{1}$ Not reported for d-fenfluramine.
} 

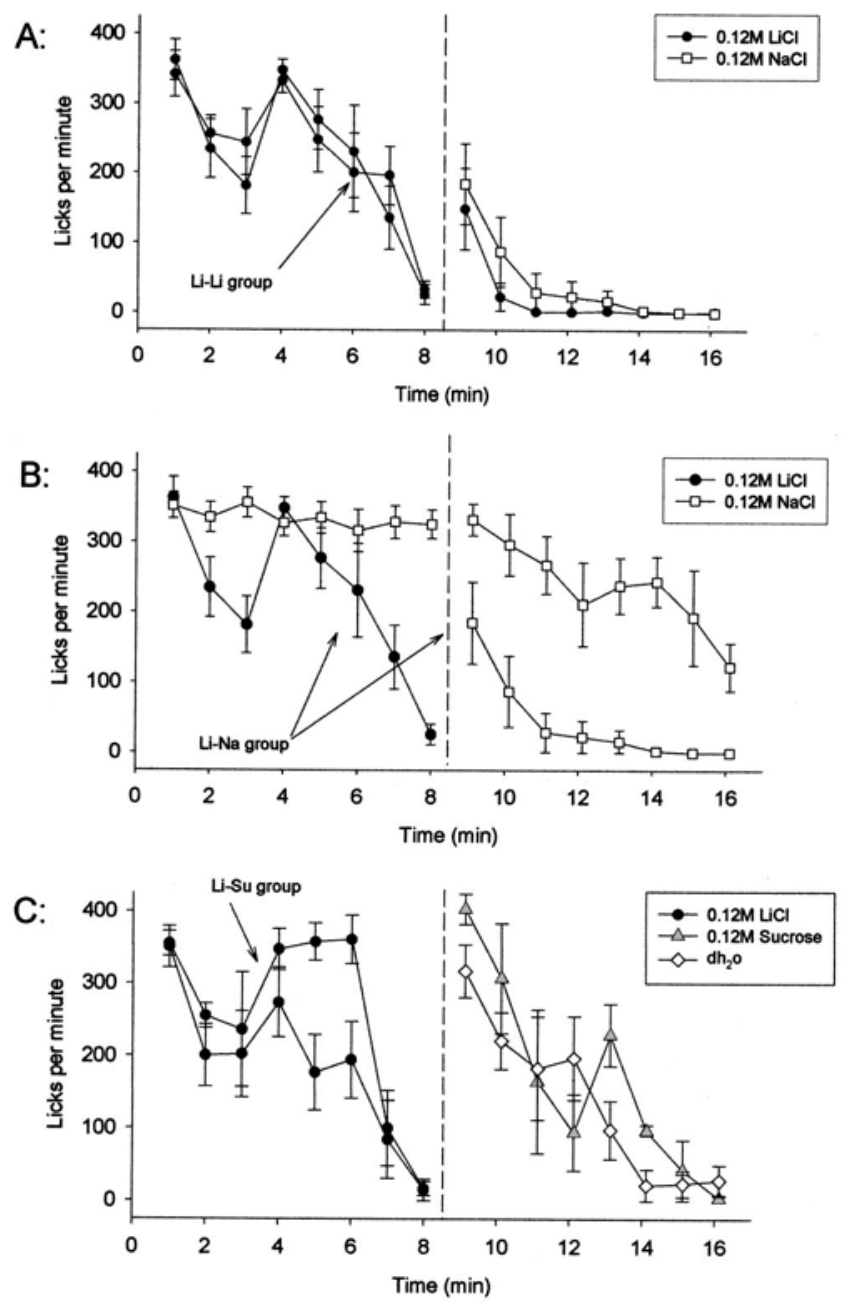

Figure 9. Mean (plus or minus standard error) lick rates (licks per minute) for rats drinking $0.12 \mathrm{M}$ lithium chloride $(\mathrm{LiCl}), 0.12 \mathrm{M}$ sodium chloride $(\mathrm{NaCl}), 0.12 \mathrm{M}$ sucrose, or distilled water $\left(\mathrm{dh}_{2} \mathrm{O}\right)$ across the first (T1) and second (T2) 8-min test session halves. Panel A: Comparison of $\mathrm{LiCl}-\mathrm{LiCl}(\mathrm{Li}-\mathrm{Li})$ and $\mathrm{LiCl}-\mathrm{NaCl}(\mathrm{Li}-\mathrm{Na})$ groups. Lick rates for both $\mathrm{LiCl}$ and $\mathrm{NaCl}$ in $\mathrm{T} 2$ were suppressed by $\mathrm{LiCl}$ ingestion in $\mathrm{T} 1 . \mathrm{T} 2$ lick rates were overlapping and not statistically different, which suggests the generalization of suppression to $\mathrm{NaCl}$. This inference is supported by Panel $\mathrm{B}$, which directly compares $\mathrm{Li}-\mathrm{Na}$ and $\mathrm{Na}-\mathrm{Na}$ groups. Panel C: Rats in the $\mathrm{LiCl}-$ sucrose $(\mathrm{Li}-\mathrm{Su})$ and $\mathrm{LiCl}-$ water groups expressed renewed lick rates for sucrose or water after $\mathrm{LiCl}$ drinking had been suppressed to minimal values by the 8th min of $\mathrm{T} 1$, which indicates that suppression of $\mathrm{T} 2 \mathrm{NaCl}$ and $\mathrm{LiCl}$ lick rates was not primarily due to malaise.

creases the incidence of ILIs in the range of $250 \mathrm{~ms}$ to $2 \mathrm{~s}$. This distributional shift appears to reflect a disruption of the Poisson process, by which behaviors that break continuation of the ongoing stereotyped lick cycle are selected (Davis, 1996); in this case, the system was biased by CTA treatment toward a much more frequent selection of behaviors that produce brief pauses. The increase in intervals ranging from $250 \mathrm{~ms}$ to $2 \mathrm{~s}$ could be due to increased expression of orofacial rejection responses that develop with CTA training (e.g., Berridge et al., 1981; Cross-Mellor, Clarke, \& Ossenkopp, 2004; Pelchat et al., 1983; Spector et al.,
1988). Pelchat et al. (1983) encoded orofacial responses to CTApaired sucrose in rats licking from a spout and observed a range of rejection behaviors, including gapes, chin rubs, forelimb flails, face washing, and head shakes. Each of these rejection behaviors can be expressed within $2 \mathrm{~s}$ in rats (John-Paul Baird, unpublished observations) but also requires more time to express than a lick cycle (about $160 \mathrm{~ms}$ ). For example, a gape cycle (the briefest rejection behavior) is typically $250 \mathrm{~ms}$ in duration (Chen \& Travers, 2003; Dinardo \& Travers, 1994). Davis (1996) suggested that ILIs in the $250-499 \mathrm{~ms}$ range represent lateral tongue protrusions (ingestive taste reactivity) or missed lick contacts, as the mean of ILIs in this range usually doubles the local lick cycle duration. However, CTA treatments reduce the incidence of tongue protrusions (Berridge et al., 1981; Eckel \& Ossenkopp, 1996; Spector et al., 1988). Although CTA may enhance missed licks, the increase in ILIs $500 \mathrm{~ms}-2$ s suggests that other nonlicking behaviors were engendered by the CTA treatment. Nevertheless, definitive proof requires a coordinated licking/electromyography and videographic analysis.

The emergence of more intervals in the $250 \mathrm{~ms}-2 \mathrm{~s}$ range, coupled with a severe reduction in burst size and no change in the mean pause duration, suggests that CTA treatment enhances processes that terminate rather than initiate bursts. Spector and St. John (1998) reached the same conclusion for the effects of QHCl on licking, observing that intact rats ingesting $\mathrm{QHCl}$ exhibited smaller bursts and a reduced initial rate of ingestion but no change in the mean pause duration relative to water ingestion. The present CTA results are comparable (see Table 2), and the failure to observe changes in mean pause duration or longer pauses may be consistent with a lack of growth of postingestive feedback inhibition during the meal because of minimal fluid intake under CTA conditions (see Spector et al., 1998).

It is unclear whether CTA treatment also affects burst initiation. The increase in burst count in the CTA conditions of Experiment 1 might have been due to thirst and/or to CTA. We believe that thirst moderates this effect because burst count was decreased for $\mathrm{T} 2 \mathrm{LiCl}$ and $\mathrm{T} 2 \mathrm{NaCl}$ drinking after $\mathrm{T} 1 \mathrm{LiCl}$ exposure (thus, hydration) in Experiment 2.

\section{CTA Produces Shifts in Hedonic Evaluation}

On first exposure to $\mathrm{LiCl}$ in Experiment 1, the rate of drinking, mean burst size, and mean pause duration in the first third of the meal were indistinguishable from those of control rats drinking $\mathrm{NaCl}$. These data support the hypothesis that $\mathrm{LiCl}$ shares a gustatory similarity with $\mathrm{NaCl}$ (Nachman, 1962, 1963a, 1963b; see also Kiefer, 1978; Ossenkopp, Ladowsky, \& Eckel, 1997; Strom, Lingenfelter, \& Brody, 1970; Trifunovic \& Reilly, 2002). In the remainder of the first $\mathrm{LiCl}$ trial, measures for $\mathrm{LiCl}$ licking markedly departed from those for $\mathrm{NaCl}$ in control rats. $\mathrm{LiCl}$ drinking shifted to a pattern of slowed ingestion characterized by bursts that were severely truncated (see Figure 3). This emergent pattern at the end of the first $\mathrm{LiCl}$ trial later typified ingestion throughout subsequent $\mathrm{LiCl}$ trials. The pattern of responses on $\mathrm{LiCl}$ Trial 3 versus water drinking was almost identical to that observed in intact rats drinking $\mathrm{QHCl}$ versus water (see Table 2). It is worth noting that in Spector and St. John (1998) an analysis of meals by thirds revealed an immediate difference in the first meal third between $\mathrm{QHCl}$ and water for burst size and drinking rate. This 
Table 9

Comparison of Water Drinking Responses After $0.12 \mathrm{M} \mathrm{LiCl}$ or $0.12 \mathrm{M} \mathrm{NaCl}$ Ingestion

\begin{tabular}{|c|c|c|c|c|c|c|}
\hline \multirow[b]{2}{*}{ Measure } & \multicolumn{2}{|c|}{$\begin{array}{c}\mathrm{T} 2 \mathrm{dH}_{2} \mathrm{O} \text { after } \\
\mathrm{T} 1 \mathrm{NaCl}\end{array}$} & \multicolumn{2}{|c|}{$\begin{array}{c}\mathrm{T} 2 \mathrm{dH}_{2} \mathrm{O} \text { after } \\
\mathrm{T} 1 \mathrm{LiCl}\end{array}$} & \multirow[b]{2}{*}{$F(1,10)$} & \multirow[b]{2}{*}{$p$} \\
\hline & $M$ & $S E$ & $M$ & $S E$ & & \\
\hline Intake $(\mathrm{ml})$ & 8.86 & 0.09 & 4.48 & 1.00 & 10.37 & .01 \\
\hline Lick count & $1,920.50$ & 87.06 & $1,090.29$ & 228.09 & 6.94 & .03 \\
\hline Lick volume $(\mu \mathrm{l})$ & 4.64 & 0.22 & 4.23 & 0.28 & 0.96 & .39 \\
\hline Drinking duration (min) & 7.63 & 0.37 & 4.73 & 0.90 & 5.39 & .05 \\
\hline Ingestion rate (licks/s) & 4.25 & 0.38 & 3.73 & 0.42 & 0.69 & .43 \\
\hline Initial lick rate & 313.50 & 30.21 & 317.43 & 36.23 & 0.01 & .94 \\
\hline Burst count & 11.75 & 2.25 & 14.43 & 3.287 & 0.32 & .59 \\
\hline Mean burst size (licks) & 184.16 & 14.07 & 80.67 & 37.60 & 9.71 & .01 \\
\hline Mean burst duration (s) & 29.39 & 5.90 & 12.36 & 1.96 & 11.48 & .01 \\
\hline Latency (s) & 9.48 & 3.85 & 63.42 & 16.35 & 5.84 & .04 \\
\hline Pause time $(\%)$ & 32.19 & 5.53 & 42.58 & 5.86 & 1.37 & .27 \\
\hline Mean pause duration (s) & 14.92 & 3.57 & 14.11 & 5.73 & 0.10 & .92 \\
\hline Pause ratio & 0.01 & 0.00 & 0.01 & 0.00 & 5.51 & .04 \\
\hline \multicolumn{7}{|l|}{ ILI range groups } \\
\hline 0-999 ms & 160.97 & 2.45 & 157.77 & 3.60 & 0.39 & .78 \\
\hline $0-249 \mathrm{~ms}$ & 154.22 & 3.04 & 143.31 & 3.40 & 4.58 & .06 \\
\hline $250-499 \mathrm{~ms}$ & 360.87 & 10.57 & 322.99 & 9.17 & 6.75 & .03 \\
\hline 500-999 ms & 717.14 & 30.26 & 721.49 & 21.76 & 0.01 & .91 \\
\hline \multicolumn{7}{|c|}{ Range proportions (\% ILIs in burst) } \\
\hline $0-249 \mathrm{~ms}$ & 97.94 & 0.33 & 94.72 & 1.50 & 2.47 & .15 \\
\hline $250-499 \mathrm{~ms}$ & 1.37 & 0.28 & 4.01 & 1.46 & 1.76 & .22 \\
\hline 500-999 ms & 0.69 & 0.20 & 1.27 & 0.22 & 3.16 & .11 \\
\hline
\end{tabular}

Note. Bold font indicates that $p$ met the criterion for statistical significance, which was set at $p \leq .05 . \mathrm{LiCl}=$ lithium chloride; $\mathrm{NaCl}=$ sodium chloride; $\mathrm{T}=$ trial; $\mathrm{dH}_{2} \mathrm{O}=$ distilled water; ILI = interlick interval.

pattern of burst responses in our experiment did not emerge immediately but rather developed gradually over the course of the first $\mathrm{LiCl}$ drinking trial in Experiment 1. This outcome supports the interpretation that the hedonic evaluation of $\mathrm{LiCl}$ was dynamically shifted from a preferred profile comparable to $\mathrm{NaCl}$ to one that paralleled bitter $\mathrm{QHCl}$ by the end of the first acquisition trial. Further, the results of Experiment 2 indicate that this change was based on a palatability shift rather than on the development of acute malaise.

In Experiment 1, the LiCl CTA generalized to both concentrations of $\mathrm{NaCl}$ but not to sucrose. $\mathrm{NaCl}$ licking on the 1st test day after $\mathrm{LiCl}$ more closely resembled licking for $\mathrm{LiCl}$ than licking for equimolar $\mathrm{NaCl}$ by the control group (see Figure 5 and Tables 3 and 4). Furthermore, the microstructural pattern of the generalization responses was not comparable to treatments that suppress intake through satiety (discussed above). These generalization results also support the hypothesis that $\mathrm{LiCl}$ exposure shifted the hedonic evaluation of $\mathrm{LiCl}$ (and, subsequently, $\mathrm{NaCl}$ ) from an appetitive to an aversive appraisal (Berridge et al., 1981; CrossMellor et al., 2004; Spector et al., 1988).

\section{Dissociation of Associative and Unconditioned Effects of $\mathrm{LiCl}$ Exposure}

The unconditioned effects of $\mathrm{LiCl}$ on drinking behavior are not easily inferred. In Experiment 1, the comparatively parallel patterns of licking for $\mathrm{NaCl}$ after $\mathrm{LiCl}$ and licking for $\mathrm{LiCl}$ itself on Acquisition Trial 3 might be taken to indicate that licking responses during $\mathrm{LiCl}$ exposure were mostly associative and not an unconditioned effect of malaise generated by $\mathrm{LiCl}$ per se. How- ever, responses during the first $\mathrm{NaCl}$ trial could include the beginnings of extinction processes. Furthermore, intake on $\mathrm{LiCl}$ Trial 3 was small, corresponding to a dose $(0.38 \mathrm{mEq} / \mathrm{kg})$ that likely produces only a moderate malaise and CTA (Nachman \& Ashe, 1973), ${ }^{2}$ and is consistent with the suggestion that rats learn to regulate $\mathrm{LiCl}$ drinking at a rate that minimizes toxicosis (CrossMellor et al., 2004). Analysis of the first $\mathrm{LiCl}$ acquisition trial to reveal the unconditioned effects of $\mathrm{LiCl}$ is also indeterminate. Although rats consumed much more $\mathrm{LiCl}$ on this trial, Experiment 2 shows that rats rapidly formed a taste-visceral association during this trial. One possible unconditioned effect of $\mathrm{LiCl}$ is that it reduces the probability of spout engagement in thirsty rats. One rat from each $\mathrm{LiCl}$ group in Experiment 2 and 1 rat in Experiment 3 (first $\mathrm{LiCl}$ trial) refused to sample the tastant offered in the $\mathrm{T} 2$ test period. Rats could have retreated from the spout because of nausea (di Lorenzo, 1988; Nachman, 1963a) or because they expected the $\mathrm{T} 2$ tastant to also be $\mathrm{LiCl}$ and simply avoided it. In opposition to the former possibility, the mean $\mathrm{T} 1 \mathrm{LiCl}$ consumption of the retreating rats $(5.92 \pm 0.93 \mathrm{~mL})$ was $33 \%$ less than that $(8.78 \pm$ $0.98 \mathrm{~mL}$ ) for rats that continued to sample during $\mathrm{T} 2$.

A comparison of licking for water offered immediately after $\mathrm{LiCl}$ or $\mathrm{NaCl}$ intake in Experiment 2 more directly indicates unconditioned $\mathrm{LiCl}$ effects. Intake for water after $\mathrm{T} 1 \mathrm{LiCl}$ exposure was reduced almost $50 \%$ in comparison with $\mathrm{T} 2$ water drinking after $\mathrm{T} 1 \mathrm{NaCl}$. This suppression cannot be attributed to differ-

\footnotetext{
${ }^{2}$ Nachman and Ashe (1973) showed that injection of $0.3 \mathrm{mEq} / \mathrm{kg} \mathrm{LiCl}$ caused a roughly $50 \%$ reduction in intake of sucrose, the conditioned stimulus.
} 
ences in $\mathrm{T} 1$ hydration because rats consumed less $\mathrm{LiCl}$ (thus, less water) compared with rats that drank $\mathrm{NaCl}$. In addition, burst size was halved, the duration of water drinking was reduced $38 \%$, and latency was significantly increased after $\mathrm{LiCl}$ (see Table 9). Nevertheless, it is clear that a large dose of $\mathrm{LiCl}$ (mean ingested = $147 \pm 16 \mathrm{mg} / \mathrm{kg}$ ) was insufficient to completely abolish ingestion in the majority (23 of 28) of thirsty rats tested; rats capably ingested appreciable volumes of water or sucrose after T1 LiCl.

It is interesting to note that Eckel and Ossenkopp (1996), Houpt and Berlin (1999), and Spector et al. (1988) failed to observe unconditioned effects of $\mathrm{LiCl}$ on intake or taste reactivity responses when rats were first tested 15 or $20 \mathrm{~min}$ after $\mathrm{LiCl}$ injection. Consistent with this finding, we observed no shifts in the ILI distribution during $\mathrm{T} 2$ water licking after $\mathrm{T} 1 \mathrm{LiCl}$ in Experiment 2, as we did for $\mathrm{LiCl}$ and $\mathrm{NaCl} \mathrm{CTA}$ conditions in both experiments. Our results support prior suggestions that the emergence of orofacial rejection responses during CTA formation is an outcome of associative taste-visceral processing (see Eckel \& Ossenkopp, 1996; Spector et al., 1988). The failure to observe a decline in intraoral intake $15 \mathrm{~min}$ after $\mathrm{LiCl}$ injection may relate to differences in route of $\mathrm{LiCl}$ delivery (intraperitoneal vs. oral), $\mathrm{LiCl}$ dose, or intake sampling method.

\section{Temporal Dynamics of CTA Formation}

The rapid generalization test design of Experiment 2 permitted us to begin to explore a temporal threshold for CTA formation. Most studies of CTA learning assess intake of the CS on a test day subsequent to acquisition training, allowing $24 \mathrm{hr}$ or more for the taste memory trace to be associated with visceral malaise. This delay conceivably allows the malaise to run its course, which could strengthen the association. In Experiment 2 we shortened the test interval to assess whether the taste association could be formed within 8 min. Licking for $\mathrm{LiCl}$ was rapidly suppressed, and a CTA was clearly formed during this time, because the suppression generalized to $\mathrm{NaCl}$ in a manner that overlapped the response to $\mathrm{T} 2 \mathrm{LiCl}$. This suppression was not principally due to malaise, because rats offered sucrose or water immediately after $\mathrm{LiCl}$ exhibited renewed and sustained licking. We conclude that CTA formation does not require significant behavioral expression of malaise (as rats actively ingested $\mathrm{LiCl}$ through most of $\mathrm{T} 1$ ) or more than 8 min to viscerally process $\mathrm{LiCl}$.

Previous studies have revealed that CTA learning occurs rapidly. Spector et al. (1988) first observed the emergence of oral rejection responses within 15 min of intraperitoneal $\mathrm{LiCl}$ injection. Eckel and Ossenkopp (1996) observed increased aversive responses 10 min after $\mathrm{LiCl}$ injection in intact rats. Houpt and Berlin (1999) showed that rats decreased intraoral sucrose intake 15 min after contingent pairing of intraoral sucrose and intraperitoneal $\mathrm{LiCl}$. The present study reduces the time to observe CTA formation to less than $9 \mathrm{~min}$. It is interesting to note that changes in taste reactivity were not observed $5 \mathrm{~min}$ after $\mathrm{LiCl}$ injection, when we observed a significant decline in $\mathrm{LiCl}$ ingestion rate (see Figure 1), and were inconsistently observed $10 \mathrm{~min}$ after injection, when we observed clear CTA generalization to $\mathrm{NaCl}$. These discrepancies could be due to differences in the route of $\mathrm{LiCl}$ delivery (intraperitoneal vs. oral), dosage (3.5 mEq/kg vs. $3 \mathrm{mEq} / \mathrm{kg})$, sampling procedure (discrete vs. continuous), or volume of CS sampled. Although CTA can be formed after only $0.1 \mathrm{~mL}$ CS tastant sampling, the strength of association increases with CS volumes through $2.5 \mathrm{~mL}$ (Barker, 1976; Peck \& Ader, 1974; T. Yamamoto, Shimura, Sako, Yasoshima, \& Sakai, 1994).

Previous studies (Baird, Travers, \& Travers, 2001) have shown that taste and gastric distension responses are integrated within the parabrachial nucleus (PBN), a brainstem nucleus necessary for CTA formation (Spector, 1995), within $90 \mathrm{~s}$, although cortical or vagal responses to intraperitoneal $\mathrm{LiCl}$ appear after 4-5 min (Niijima \& Yamamoto, 1994; Yamamoto \& Yuyama, 1987). Several studies (Chang \& Scott, 1984; McCaughey, Giza, Nolan, \& Scott, 1997; Shimura, Tanaka, \& Yamamoto, 1997; Shimura, Tokita, \& Yamamoto, 2002; Tamura \& Norgren, 1997) have shown significant differences in neural gustatory coding in the PBN or nucleus of the solitary tract between groups of rats with or without prior CTA training, although evidence of single-neuron shifts is limited to one study of insular cortex recordings (Yasoshima \& Yamamoto, 1998). The rapid formation of CTA evidenced here suggests that direct, real-time neural evidence of CTA formation can be obtained at other nuclei implicated in CTA (e.g., the $\mathrm{PBN})$.

\section{Extinction}

Although CTA profoundly changed several microstructural measures, rats exhibited rapid extinction such that all measures except intake and lick volume were comparable to control conditions by the third extinction trial for $0.12 \mathrm{M} \mathrm{NaCl}$. Extinction rates reported in the literature vary considerably as a result of the extent of food or water deprivation, time of testing, and method of CS delivery (e.g., Abelson, Pierrel-Sorrentino, \& Blough, 1977; Fouquet, Oberling, \& Sandner, 2001; Nolan et al., 1997; Ternes, 1976; J. Yamamoto, Fresquet, \& Sandner, 2002). In Experiment 1 rats had only $15 \mathrm{~min}$ fluid access every $24 \mathrm{hr}$. This likely resulted in more frequent CS sampling (increased burst count) for purposes of hydration, resulting in a rapid extinction within three trials. This outcome supports observations that CTA learning obeys Pavlovian extinction principles provided that adequate CS sampling occurs under extinction conditions (e.g., Wolgin \& Wade, 1990).

Extinction occurred rapidly but in a graded fashion across trials (see Figure 7). It is interesting to note that although most microstructural measures had recovered by the third trial, two lagging indicators of this recovery were lick volume and intake (see Table 6 ). This outcome suggests the provocative notion that intake per se may be a less sensitive measure of aversion and extinction than licking microstructure and taste reactivity measures. For example, ICV CART infusions produced rightward shifts in the ILI distribution, indicating a slower lick rate within bursts (as observed here under CTA), at a dose of CART $(0.5 \mu \mathrm{g})$ that was subthreshold to the dose necessary to suppress intake $(1 \mu \mathrm{g})$ and cause a CTA (Aja et al., 2001, 2002). However, further work is needed to explicitly compare licking microstructure or taste reactivity measures at doses of an emetic agent that straddle the intake threshold for CTA formation.

\section{Limitations}

The microstructural changes induced by CTA in this study may not be pertinent to other forms of CTA. For example, ICV CART infusions produced a CTA, tremors, and slowing of ingestion rate 
and intraburst lick rate but had no effect on burst size or number as observed with CTAs in this study. Researchers should test additional forms of CTA (e.g., different emetics and different tastants) with a microstructural analysis to assess the general validity of the present outcomes. Several studies have reliably characterized the effects of other intake-modifying treatments on licking microstructure for normally preferred tastants. We believe that the present study provides normative data that contribute to a growing literature on licking microstructure for aversive tastants. One may argue that without significant motivation (e.g., thirst) animals would not ingest aversive tastants. However, many natural foods (e.g., fruits) contain mixtures of both palatable and aversive taste stimuli. Furthermore, a better understanding of the character of licking responses to a variety of gustatory stimuli, including aversive stimuli, could help to reveal the functional underpinnings of novel treatments that affect intake (see Grill, Spector, Schwartz, Kaplan, \& Flynn, 1987, for discussion). Nevertheless, it should be noted that rats express considerable behavioral flexibility when intake access is challenged. We recently showed that explicit manipulation of lick volume produced marked shifts in the licking pattern with no overall effect on the intake outcome (Kaplan et al., 1997, 2001; Williams et al., 2002). Although licking parameters are not strictly fixed to sensory or state variables, microstructural analysis appears to have exploratory value to the extent that effects can be reliably observed and replicated under constant conditions. For example, in this study we observed a reliable within- and across-experiments replication of the pattern of behavioral microstructure for $\mathrm{LiCl}$ licking in seven separate groups of rats.

\section{Perspectives}

Taste reactivity analyses show that CTA treatments produce conditioned sucrose responses that resemble those for $\mathrm{QHCl}$ in untreated rats (Berridge et al., 1981; Cross-Mellor et al., 2004; Eckel \& Ossenkopp, 1996; Pelchat et al., 1983). The pattern of licking microstructure also shifted to resemble $\mathrm{QHCl}$ licking during and after CTA treatment (see Table 2). The congruence of the outcomes of these two methods strongly supports the theory that CTA treatments produce an acquired dislike for once-preferred tastants in rats and humans alike (Pelchat \& Rozin, 1982).

As a measure of hedonic evaluation, each method offers different strengths. Taste reactivity analysis provides categorical data and can use intraoral infusions to ensure uniform CS sampling. Licking microstructure analysis provides a wider array of response measurements and permits a less cumbersome analysis of behavior continuously throughout the test session, with millisecond resolution. This technique may therefore provide an effective and efficient means to evaluate both the quantitative (intake) and the qualitative (hedonic evaluation) effects of novel treatments and help to distinguish whether intake effects are due to catatonia, malaise, satiety, or other factors.

In Experiment 2 we developed a rapid CTA generalization test. We believe that this paradigm could be used to build on the efforts of Spector et al. (1988) to distinguish the differential effects of particular treatments that block CTA processing, such as parabrachial lesions (e.g., Spector, 1995), amygdala lesions (e.g., Lasiter \& Glanzman, 1985), and the Glucagon-like peptide-1 antagonist exendin (Kinzig, D’Alessio, \& Seeley, 2002), may have on specific stages of CTA processing (Spector et al., 1988). Spector et al.
(1988) noted that CTAs could be blocked because of impairment of taste sensation, visceral sensation, taste-visceral integration, or long-term memory processing of the CTA. To first rule out dysgeusic effects of the treatment, researchers can use brief access tests to evaluate gustatory concentration-response functions and taste thresholds (e.g., Koh \& Teitelbaum, 1961; J. C. Smith, Davis, \& O'Keefe, 1992; Spector, Grill, \& Norgren, 1993). With the inclusion of a follow-up generalization test, the rapid generalization method of Experiment 2 could be used to evaluate whether the treatment affects any of the three remaining stages of CTA processing. If the CTA-blocking treatment renders rats insensitive to peripheral malaise, then $\mathrm{LiCl}$ intake should not be suppressed at all during the $\mathrm{T} 1 \mathrm{LiCl}$ drinking phase, as one unconditioned effect of $\mathrm{LiCl}$ was partial intake suppression (see Table 9). If the treatment selectively blocks taste-visceral association, then $\mathrm{LiCl}$ drinking should be suppressed, but this should not generalize to $\mathrm{NaCl}$ (relative to other tastants) offered seconds later (di Lorenzo, 1998; Trifunovic \& Reilly, 2002). Finally, if long-term processing of the CTA is disrupted, rats will show generalization to $\mathrm{NaCl}$ in the single test but fail to show generalization when offered $\mathrm{NaCl}$ on a subsequent test day. Thus, this rapid generalization testing method could help to distinguish the relative contributions of pharmacological and neurologic treatments to CTA function and to tastevisceral integration in general.

\section{References}

Abelson, J. S., Pierrel-Sorrentino, R., \& Blough, P. M. (1977). Some conditions for the rapid extinction of a learned taste aversion. Bulletin of the Psychonomic Society, 9, 51-52.

Aja, S., Robinson, B. M., Mills, K. J., Ladenheim, E. E., \& Moran, T. H. (2002). Fourth ventricular CART reduces food and water intake and produces a conditioned taste aversion in rats. Behavioral Neuroscience, 116, 918-921.

Aja, S., Schwartz, G. J., Kuhar, M. J., \& Moran, T. H. (2001). Intracerebroventricular CART peptide reduces rat ingestive behavior and alters licking microstructure. American Journal of Physiology, 280, R1613R1619.

Baird, J. P., Grill, H. J., \& Kaplan, J. M. (1999). Effect of hepatic glucose infusion on glucose intake and licking microstructure in deprived and nondeprived rats. American Journal of Physiology, 277, R1136-R1143.

Baird, J. P., Travers, S. P., \& Travers, J. B. (2001). Integration of gastric distension and gustatory responses in the parabrachial nucleus. American Journal of Physiology, 281, R1581-R1593.

Barker, L. (1976). CS duration, amount, and concentration effects in conditioning taste aversions. Learning and Motivation, 7, 265-273.

Bernstein, I. L. (1985). Learned food aversions in the progression of cancer and its treatment. Annals of the New York Academy of Sciences, 443, 365-380.

Bernstein, I. L. (1999). Taste aversion learning: A contemporary perspective. Nutrition, 15, 229-234.

Berridge, K., Grill, H. J., \& Norgren, R. (1981). Relation of consummatory responses and preabsorptive insulin release to palatability and learned taste aversions. Journal of Comparative and Physiological Psychology, 95, 363-382.

Chang, F. C., \& Scott, T. R. (1984). Conditioned taste aversions modify neural responses in the rat nucleus tractus solitarius. Journal of Neuroscience, 4, 1850-1862.

Chen, Z., \& Travers, J. B. (2003). Inactivation of amino acid receptors in medullary reticular formation modulates and suppresses ingestion and rejection responses in the awake rat. American Journal of Physiology, 285, R68-R83. 
Cross-Mellor, S., Clarke, S. N., \& Ossenkopp, K. P. (2004). Rapid toxininduced gustatory conditioning in rats: Separate and combined effects of systemic injection or intraoral infusion of lithium chloride. Behavioural Brain Research, 154, 423-430.

Davis, J. D. (1996). Deterministic and probabilistic control of the behavior of rats ingesting liquid diets. American Journal of Physiology, 270, R793-R800.

Davis, J. D. (1998). A model for the control of ingestion-20 years later. Progress in Psychobiology and Physiological Psychology, 17, 127-173.

Davis, J. D., \& Perez, M. C. (1993). Food deprivation- and palatabilityinduced microstructural changes in ingestive behavior. American Journal of Physiology, 264, R97-R103.

Davis, J. D., \& Smith, G. P. (1992). Analysis of the microstructure of the rhythmic tongue movements of rats ingesting maltose and sucrose solutions. Behavioral Neuroscience, 106, 217-228.

Davis, J. D., Smith, G. P., \& Kung, T. M. (1995). Cholecystokinin changes the duration but not the rate of licking in vagotomized rats. Behavioral Neuroscience, 109, 991-996.

di Lorenzo, P. M. (1988). Long-delay learning in rats with parabrachial pontine lesions. Chemical Senses, 13, 219-229.

Dinardo, L. A., \& Travers, J. B. (1994). Hypoglossal neural activity during ingestion and rejection in the awake rat. Journal of Neurophysiology, 72, 1181-1191.

Eckel, L. A., \& Ossenkopp, K.-P. (1996). Area postrema mediates the formation of rapid, conditioned palatability shifts in lithium-treated rats. Behavioral Neuroscience, 110, 202-212.

Eisen, S., Davis, J. D., Rauhofer, E., \& Smith, G. P. (2001). Gastric negative feedback produced by volume and nutrient during a meal in rats. American Journal of Physiology, 281, R1201-R1214.

Fouquet, N., Oberling, P., \& Sandner, G. (2001). Differential effect of free intake versus oral perfusion of sucrose in conditioned taste aversion in rats. Physiology and Behavior, 74, 465-474.

Garcia, J., Kimeldorf, D. J., \& Koelling, R. A. (1955, July 22). Conditioned aversion to saccharin resulting from exposure to gamma radiation. Science, 122, 157-158.

Grill, H. J., Spector, A. C., Schwartz, G. J., Kaplan, J. M., \& Flynn, F. W. (1987). Evaluating taste effects on ingestive behavior. In F. M. Toates \& N. R. Rowland (Eds.), Methods for the study of feeding and drinking (pp. 151-188). New York: Elsevier.

Houpt, T. A., \& Berlin, R. (1999). Rapid, labile, and protein synthesisindependent short-term memory in conditioned taste aversion. Learning \& Memory, 6, 37-46.

Hsiao, S., \& Fan, R. J. (1993). Additivity of taste-specific effects of sucrose and quinine: Microstructural analysis of ingestive behavior in rats. Behavioral Neuroscience, 107, 317-326.

Jacobsen, P. B., Bovbjerg, D. H., Schwartz, M. D., Andrykowski, M. A., Futterman, A. D., Gilewski, T., et al. (1993). Formation of food aversions in cancer patients receiving repeated infusions of chemotherapy. Behaviour Research and Therapy, 31, 739-748.

Kaplan, J. M., Baird, J. P., \& Grill, H. J. (2001). Dissociation of licking and volume intake controls in rats ingesting glucose and maltodextrin. $B e-$ havioral Neuroscience, 115, 188-195.

Kaplan, J. M., Donahey, J., Baird, J. P., Simansky, K. J., \& Grill, H. J. (1997). d-fenfluramine anorexia: Dissociation of ingestion rate, meal duration, and meal size effects. Pharmacology, Biochemistry, and Behavior, 57, 223-229.

Kent, W. D., Cross-Mellor, S. K., Kavaliers, M., \& Ossenkopp, K. P. (2002). Acute effects of corticosterone on LiCl-induced rapid gustatory conditioning in rats: A microstructural analysis of licking patterns. Behavioural Brain Research, 136, 143-150.

Kiefer, S. W. (1978). Two-bottle discrimination of equimolar $\mathrm{NaCl}$ and LiCl solutions by rats. Physiological Psychology, 6, 191-198.

Kinzig, K. P., D’Alessio, D. A., \& Seeley, R. J. (2002). The diverse roles of specific GLP-1 receptors in the control of food intake and the response to visceral illness. Journal of Neuroscience, 22, 10470-10476.

Koh, S. D., \& Teitelbaum, P. (1961). Absolute behavioral taste thresholds in the rat. Journal of Comparative and Physiological Psychology, 54, 223-229.

Lasiter, P. S. (1985). Thalamocortical relations in taste aversion learning: II. Involvement of the medial ventrobasal thalamic complex in taste aversion learning. Behavioral Neuroscience, 99, 477-495.

Lasiter, P. S., \& Glanzman, D. L. (1985). Cortical substrates of taste aversion learning: Involvement of dorsolateral amygdaloid nuclei and temporal neocortex in taste aversion learning. Behavioral Neuroscience, 99, 257-276.

Loy, I., \& Hall, G. (2002). Taste aversion after ingestion of lithium chloride: An associative analysis. Quaterly Journal of Experimental Psychology B, 55, 365-380.

McCaughey, S. A., Giza, B. K., Nolan, L. J., \& Scott, T. R. (1997). Extinction of a conditioned taste aversion in rats: II. Neural effects in the nucleus of the solitary tract. Physiology \& Behavior, 61, 373-379.

Nachman, M. (1962). Taste preferences for sodium salts by adrenalectomized rats. Journal of Comparative and Physiological Psychology, 55, $1124-1129$.

Nachman, M. (1963a). Learned aversion to the taste of lithium chloride and generalization to other salts. Journal of Comparative and Physiological Psychology, 56, 343-349.

Nachman, M. (1963b). Taste preference for lithium chloride by adrenalectomized rats. American Journal of Physiology, 205, 219-221.

Nachman, M., \& Ashe, J. H. (1973). Learned taste aversions in rats as a function of dosage, concentration, and route of administration of $\mathrm{LiCl}$. Physiology \& Behavior, 10, 73-78.

Niijima, A., \& Yamamoto, T. (1994). The effects of lithium chloride on the activity of the afferent nerve fibers from the abdominal visceral organs in the rat. Brain Research Bulletin, 35(2), 141-145.

Nolan, L. J., McCaughey, S. A., Giza, B. K., Rhinehart-Doty, J. A., Smith, J. C., \& Scott, T. R. (1997). Extinction of a conditioned taste aversion in rats: I. Behavioral effects. Physiology \& Behavior, 61, 319-323.

Ossenkopp, K.-P., Ladowsky, R. L., \& Eckel, L. A. (1997). Forced-choice discrimination of equimolar $\mathrm{NaCl}$ and $\mathrm{LiCl}$ solutions in rats: Effects of ablating the chemosensitive area postrema on acquisition and retention. Behavioural Brain Research, 87, 15-24.

Peck, J., \& Ader, R. (1974). Illness-induced taste aversion under states of deprivation and satiation. Animal Learning \& Behavior, 2(1), 6-8.

Pelchat, M. L., Grill, H. J., Rozin, P., \& Jacobs, J. (1983). Quality of acquired responses to tastes by Rattus norvegicus depends on type of associated discomfort. Journal of Comparative Psychology, 97, 140153.

Pelchat, M. L., \& Rozin, P. (1982). The special role of nausea in the acquisition of food dislikes by humans. Appetite, 3, 341-351.

Rhinehart-Doty, J. A., Schumm, J., Smith, J. C., \& Smith, G. P. (1994). A non-taste cue of sucrose in short-term taste tests in rats. Chemical Senses, 19, 425-431.

Riley, A. L., \& Freeman, K. B. (2003). Conditioned taste aversion: An annotated bibliography [Searchable database]. Retrieved January 14, 2004, from http://www.ctalearning.com

Rodriguez, M., Lopez, M., Symonds, M., \& Hall, G. (2000). Lithiuminduced context aversion in rats as a model of anticipatory nausea in humans. Physiology \& Behavior, 71, 571-579.

Seeley, R. J., Payne, C. J., \& Wood, S. C. (1995). Neuropeptide Y fails to increase intraoral intake in rats. American Journal of Physiology, 268, R423-R427.

Shimura, T., Tanaka, H., \& Yamamoto, T. (1997). Salient responsiveness of parabrachial neurons to the conditioned stimulus after the acquisition of taste aversion learning in rats. Neuroscience, 81, 239-247.

Shimura, T., Tokita, K., \& Yamamoto, T. (2002). Parabrachial unit activ- 
ities after the acquisition of conditioned taste aversion to a non-preferred HCL solution in rats. Chemical Senses, 27, 153-158.

Smith, G. P. (2001). John Davis and the meanings of licking. Appetite, 36, 84-92.

Smith, J. C., Davis, J. D., \& O'Keefe, G. B. (1992). Lack of an order effect in brief contact taste tests with closely spaced test trials. Physiology \& Behavior, 52, 1107-1111.

Spector, A. C. (1995). Gustatory function in the parabrachial nuclei: Implications from lesion studies in rats. Reviews in Neuroscience, 6 , 143-175.

Spector, A. C., Breslin, P., \& Grill, H. J. (1988). Taste reactivity as a dependent measure of the rapid formation of conditioned taste aversion: A tool for the neural analysis of taste-visceral associations. Behavioral Neuroscience, 102, 942-952.

Spector, A. C., Grill, H. J., \& Norgren, R. (1993). Concentration-dependent licking of sucrose and sodium chloride in rats with parabrachial gustatory lesions. Physiology \& Behavior, 53, 277-283.

Spector, A. C., Klumpp, P. A., \& Kaplan, J. M. (1998). Analytical issues in the evaluation of food deprivation and sucrose concentration effects on the microstructure of licking behavior in the rat. Behavioral Neuroscience, 112, 678-694.

Spector, A. C., \& St. John, S. J. (1998). Role of taste in the microstructure of quinine ingestion by rats. American Journal of Physiology, 274, R1687-R1703.

Strom, C., Lingenfelter, A., \& Brody, J. F. (1970). Discrimination of lithium and sodium chloride. Psychonomic Science, 18, 290-291.

Tamura, R., \& Norgren, R. (1997). Repeated sodium depletion affects gustatory neural responses in the nucleus of the solitary tract of rats. American Journal of Physiology, 273, R1381-R1391.

Ternes, J. W. (1976). Resistance to extinction of a learned taste aversion varies with time of conditioning. Animal Learning \& Behavior, 4, 317-321.

Travers, J. B., Dinardo, L. A., \& Karimnamazi, H. (1997). Motor and premotor mechanisms of licking. Neuroscience and Biobehavioral Reviews, 21, 631-647.

Trifunovic, R., \& Reilly, S. (2002). Medial versus lateral parabrachial nucleus lesions in the rat: Effects on mercaptoacetate-induced feeding and conditioned taste aversion. Brain Research Bulletin, 58(1), 107-113.

Weijnen, J. A. (1998). Licking behavior in the rat: Measurement and situational control of licking frequency. Neuroscience \& Biobehavioral Reviews, 22, 751-760.

Welzl, H., D'Adamo, P., \& Lipp, H. P. (2001). Conditioned taste aversion as a learning and memory paradigm. Behavioural Brain Research, 125, 205-213.

Williams, D. L., Grill, H. J., Weiss, S. M., Baird, J. P., \& Kaplan, J. M. (2002). Behavioral processes underlying the intake suppressive effects of melanocortin 3/4 receptor activation in the rat. Psychopharmacology, 161(1), 47-53.

Wolgin, D. L., \& Wade, J. V. (1990). Effect of lithium chloride-induced aversion on appetitive and consummatory behavior. Behavioral Neuroscience, 104, 438-440.

Yamamoto, J., Fresquet, N., \& Sandner, G. (2002). Conditioned taste aversion using four different means to deliver sucrose to rats. Physiology \& Behavior, 75, 387-396.

Yamamoto, T., Shimura, T., Sako, N., Yasoshima, Y., \& Sakai, N. (1994). Some critical factors involved in formation of conditioned taste aversion to sodium chloride in rats. Chemical Senses, 19, 209-217.

Yamamoto, T., \& Yuyama, N. (1987). On a neural mechanism for cortical processing of taste quality in the rat. Brain Research, 400, 312-320.

Yasoshima, Y., \& Yamamoto, T. (1998). Short-term and long-term excitability changes of the insular cortical neurons after the acquisition of taste aversion learning in behaving rats. Neuroscience, 84, 1-5.

Received February 9, 2005

Revision received April 15, 2005

Accepted April 22, 2005 